University of Warwick institutional repository: http://go.warwick.ac.uk/wrap This paper is made available online in accordance with publisher policies. Please scroll down to view the document itself. Please refer to the repository record for this item and our policy information available from the repository home page for further information.

To see the final version of this paper please visit the publisher's website. Access to the published version may require a subscription.

Author(s): Elizabeth A. Maylor, Bartley Sheehan, Derrick G. Watson and Emma L. Henderson

Article Title: Enumeration in Alzheimer's disease and other late life psychiatric syndromes

Year of publication: 2008

Link to published version:

http://dx.doi.org/10.1016/j.neuropsychologia.2008.05.002

Publisher statement: None 
Running head: ENUMERATION IN DEMENTIA

Enumeration in Alzheimer's Disease and Other Late Life Psychiatric Syndromes

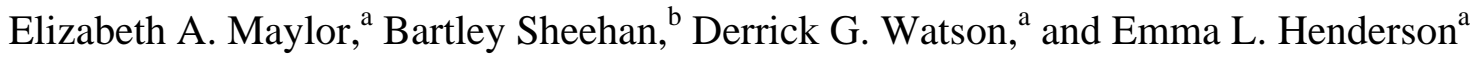
${ }^{\mathrm{a}}$ Department of Psychology, University of Warwick, UK

${ }^{\mathrm{b}}$ Warwick Medical School, University of Warwick, UK

Corresponding author:

Elizabeth A Maylor

Department of Psychology

University of Warwick

Coventry CV4 7AL

UK

Tel: +44 2476524926

Fax: +44 2476524225

Email: e.a.maylor@warwick.ac.uk

Acknowledgment: This work was funded by Research into Ageing (Grant No. 283). 


\begin{abstract}
Previous studies suggest that visual enumeration is spared in normal aging but impaired in abnormal aging (late stage Alzheimer's disease, AD), raising the task's potential as a marker of dementia. Experiment 1 compared speeded enumeration of 1-9 random dots in early stage AD, vascular dementia (VAD), depression, and age-matched controls. Previous deficits were replicated but they were not specific to $\mathrm{AD}$, with the rate of counting larger numerosities similarly slowed relative to controls by both AD and VAD. Determination of subitizing span was complicated by the surprisingly slower enumeration of one than of two items, especially in $\mathrm{AD}$ patients. Experiment 2 showed that $\mathrm{AD}$ patients' relative difficulty with one item persisted with further practice and extended to the enumeration of targets among distractors. However, it was abolished when pattern recognition was possible (enumerating dots on a die). Although an enumeration test is unlikely to help differentiate early AD from other common dementias, the unexpected pattern of patients' performance challenges current models of enumeration and requires further investigation.
\end{abstract}

Keywords: subitizing; counting; vascular dementia; depression; aging; visual search 
Enumeration in Alzheimer's Disease and Other Late Life Psychiatric Syndromes

With recent increases in both the number and proportion of older adults in western societies (Laslett, 1997), and the probability of developing dementia rising exponentially with age (Hofman et al., 1991), dementia has become a major public health concern (Fratiglioni \& Rocca, 2001). For example, Hebert, Scherr, Bienias, Bennett, and Evans (2003) estimated that, in 2000, 4.5 million people in the US were suffering from Alzheimer's disease (AD), the most common form of dementia. Earlier diagnosis will always assist planning of rational management (Albert, 2008) but because the presence of AD can only be confirmed at autopsy, there are at least three difficulties associated with the diagnosis and hence treatment of patients with AD. First, global impairment of higher cortical functions is evident not only in dementia but also in normal aging in comparison with younger adults. In other words, deficits seen in AD are often characterized as merely exaggerated versions of deficits seen in normal aging (Nebes, 1992; Nebes \& Brady, 1992). It can therefore be difficult, particularly in the early stages of the disease, to determine whether patients are experiencing greater cognitive decline than would be expected for their age. Second, it is important to distinguish AD from other dementias such as vascular dementia (VAD). Third, dementia must be distinguished from conditions that may mimic it (pseudodementia); for example, depression can result in many of the cognitive changes seen in $\mathrm{AD}$ as depressed patients lose motivation and interest in their surroundings and perform poorly on tests of memory and intellect (Woods, 1999).

Maylor, Watson, and Muller (2005) identified a simple task (enumeration) that would appear to provide a rare example of a qualitative difference between the effects of normal aging and AD. Their data suggested that whereas enumeration ability is exceptionally spared in normal older adults, aspects of enumeration performance are significantly impaired in AD patients. This raises the possibility that enumeration tasks could be a valuable tool for use in 
the diagnosis of, and early screening for, AD. However, this would require, at minimum, evidence that the deficits observed by Maylor et al. are specific to AD and are clearly found in its early stages. The first main aim of the present study was therefore to extend previous work by comparing enumeration performance of $\mathrm{AD}$ patients with that of patients with other late life psychiatric syndromes (Experiment 1). The second was to explore different explanations for the unusual pattern of enumeration data seen in AD patients (Experiment 2).

\section{Visual Enumeration}

In a speeded enumeration task, participants are typically asked to indicate as quickly as possible how many items (often 1-9) are present in a visual display. Response times (RTs) plotted as a function of numerosity usually result in a bilinear function, with a discontinuity or flex point between 3 and 4 items. Up to the flex point, RTs increase relatively little (usually <100 ms/item) and errors are rare; beyond this point, RTs increase more substantially with each additional item ( 350 ms/item) and errors grow in frequency (e.g., Trick \& Pylyshyn, 1993, 1994). The fast and accurate enumeration of small numbers of items is termed subitizing, and the slower and less accurate enumeration of larger numbers of items is termed counting (see Kaufman, Lord, Reese, \& Volkman, 1949; Mandler \& Shebo, 1982; Sagi \& Julesz, 1984; Trick \& Pylyshyn, 1993, 1994). The flex point of the bilinear function fit to the data can be used to determine the subitizing span (e.g., Watson, Maylor, Allen, \& Bruce, 2007).

A number of explanations have been proposed to account for the bilinear enumeration function (e.g., Gallistel \& Gelman, 1992; Logan \& Zbrodoff, 2003; Mandler \& Shebo, 1982), but the currently most comprehensive account is that of Trick and Pylyshyn (1993, 1994). They proposed that the visual system can selectively tag or assign pointers (termed FINSTs, for fingers of instantiation) to items in a display that can be individuated at a preattentive level of processing. The number of FINSTs is limited to around four - hence 
small numbers of items can be enumerated by directly determining the total number of FINSTs currently bound to items in the display (subitizing). When the number of items exceeds the number of FINSTs, enumeration proceeds via a serial process of disengaging and reassigning FINSTs to the remaining items, maintaining a running total, recording which items have been counted, and so on. These additional relatively complex operations result in a substantial and linear increase in RT as a function of numerosity (counting).

Neural evidence is somewhat mixed but generally supports the notion of subitizing and counting as qualitatively distinct processes. Thus, positron emission tomography studies have found that counting produces greater activation than does subitizing (Piazza, Mechelli, Butterworth, \& Price, 2002) and involves a wider network of brain regions (fronto-parietal areas for counting, occipital areas for subitizing; Sathian et al., 1999). Also, a functional magnetic resonance imaging study by Piazza, Giacomini, Le Bihan, and Dehaene (2003) showed a sudden increase in activation in fronto-parietal regions associated with shifts of spatial attention and updating of working memory when subitizing span was exceeded. Finally, patients with parietal damage can show impaired counting but preserved subitizing (Dehaene \& Cohen, 1994; Watson \& Humphreys, 1999).

\section{Enumeration in Normal Aging and Dementia}

Many visual/attentional tasks produce marked age-related deficits that are largely consistent with general (proportional) slowing in old age (e.g., slower search for a target among distractors; Hommel, Li, \& Li, 2004; for summaries, see Kramer \& Madden, 2008; Madden \& Whiting, 2004). Visual enumeration is a striking exception to this pattern because, at least in the absence of distractors, normal older adults may be slower overall than young adults but their subitizing spans and counting rates are unimpaired (see Maylor \& Watson, 2005, for a review). Thus, instead of the usual increase in age differences with task complexity (Birren, 1965; Cerella, Poon, \& Williams, 1980; Salthouse, 1985), the RT- 
numerosity functions for enumeration are approximately parallel for young and older adults (e.g., Basak \& Verhaeghen, 2003; Watson, Maylor, Allen, \& Bruce, 2007; Watson, Maylor, \& Bruce, 2005a, 2005b; Watson, Maylor, \& Manson, 2002).

Fewer studies have examined enumeration in dementia. Those only reporting accuracy in enumerating up to nine dots have found no differences between AD patients and age-matched controls (Boone et al., 2002; Delazer, Karner, Proell, \& Benke, 2006; Fujimori, Imamura, Yamashita, Hirono, \& Mori, 1997; Halpern, McMillan, Moore, Dennis, \& Grossman, 2003). However, there is evidence from more sensitive speeded tasks that enumeration rates may be impaired in AD (Kaufmann et al., 2002; Maylor et al., 2005; Nebes, Brady, \& Reynolds, 1992). In particular, Maylor et al. assessed speeded enumeration of 1-9 randomly arranged circles in $12 \mathrm{AD}$ patients and 8 age-matched controls (mean ages of 80). As expected, AD patients were slower overall than controls (2947 vs. 1536 ms). Moreover, subitizing span was significantly reduced in AD patients compared with controls (2.32 vs. 3.45 items) and, for larger numerosities, counting rate was significantly slower in patients than in controls (451 vs. 349 ms/item). Importantly, there was minimal overlap between groups as no AD patient had both a subitizing span and a counting rate within the ranges of controls. Finally, the enumeration deficits of the AD patients were significantly correlated with severity of dementia as measured by scores on the Mini-Mental State Examination (MMSE; Folstein, Folstein, \& McHugh, 1975).

Together, these results suggest qualitative differences between enumeration in normal aging and dementia (see Nebes, 1992; Nebes \& Madden, 1988, on the importance of such differences), with subitizing span and counting rate both preserved in normal aging but impaired in $\mathrm{AD}$. A slower counting rate in $\mathrm{AD}$ would be consistent with known diseaserelated damage to both frontal and parietal lobes (e.g., Albert, 2008) and its corresponding effects on memory and attention (e.g., Parasuraman \& Greenwood, 1998). It is also 
consistent with dementia-related general slowing such that the absolute difference in RT between patients and controls increases as task complexity increases (e.g., Foster, Behrmann, \& Stuss, 1999; Nebes \& Brady, 1989, 1992; Nestor, Parasuraman, \& Haxby, 1991). However, a reduction in subitizing span fits less well with the relative sparing of the occipital lobes in AD (Albert, 2008), and it cannot easily be accommodated by generalized slowing theories. Instead, a decrease in subitizing span with AD could be interpreted within the FINST framework as a reduction in the number of available FINSTs, a deficit that could also be the source of several other attentional/cognitive deficits seen in $\mathrm{AD}$ (e.g., Amieva, Phillips, Della Sala, \& Henry, 2004; Perry \& Hodges, 1999; see Maylor et al., 2005, for discussion).

\section{Experiment 1}

There were two main aims: (i) to discover if the enumeration deficits observed in Maylor et al.'s (2005) study of AD patients in the moderate stage of the disease (mean MMSE score of 17.3) are also present in newly diagnosed (mild stage) patients, and (ii) to explore whether the enumeration deficits are specific to AD by comparing the performance of four groups of age- and education-matched adults over the age of 65, namely, AD patients, patients with vascular dementia (VAD) - the second most common dementia in community studies in western countries (Fratiglioni \& Rocca, 2001; Stevens et al., 2002), depressed patients, and healthy controls. As far as we are aware, there have been no previous studies of speeded enumeration in VAD patients, but it might be expected that they would show counting rate deficits in line with known frontal lobe damage (Desmond, 2004) and associated deficits in processing speed and attention/executive functioning (Graham, Emery, \& Hodges, 2004). There have been two studies of speeded enumeration in depressed patients (Lee et al., 2000; Nebes et al., 1992), with no obvious qualitative differences between their performance and that of age-matched controls. However, no-one has examined performance 
over both the subitizing and counting ranges in depression. It might be expected that depressed patients would be slower overall than controls because of motor retardation (e.g., Nebes, Halligan, Rosen, \& Reynolds, 1998) and show a slower counting rate because of reduced information processing speed and working memory/attentional/executive impairments in late life depression (e.g., Nebes et al., 2000; Sheline et al., 2006; Steffens \& Potter, 2008; Thomas \& O’Brien, 2008), but that subitization should be spared on the basis that depression interferes minimally with automatic processes (e.g., Hartlage, Alloy, Vazquez, \& Dykman, 1993). Participants in each group completed background tests to assess visual, mental and cognitive status. These were followed by multiple blocks of speeded enumeration trials in which participants determined as quickly and as accurately as possible the number of randomly arranged dots (between 1 and 9) displayed on a computer screen.

Method

Participants. Patients were recruited from consecutive new cases referred to a clinical old age psychiatry service in Coventry, UK. The second author reviewed all new cases to establish matches with eligibility criteria. AD patients were diagnosed as suffering from progressive cognitive deterioration due to probable AD according to the National Institute of Neurological and Communicable Disease and Stroke--Alzheimer's Disease and Related Disorders Association’s guidelines (McKhann et al., 1984) based on medical, neurological and psychiatric examination. VAD patients and patients with major depression (DEP) were diagnosed according to the Diagnostic and Statistical Manual of Mental Disorders (DSM-IV; American Psychiatric Association, 1994). Patients were identified as eligible for the study if they had 'pure' diagnoses, were over 65 years of age, free from life threatening illness and willing to take part (33 AD; 11 VAD; 22 DEP). Of these 66 patients, 49 were able to be visited for testing (24 AD; 8 VAD; 17 DEP) of whom 40 provided data 
that were included in the final analyses (19 AD; 6 VAD; 15 DEP; see Table 1). The nine patients who either dropped out at some point during the testing session or provided unusable (outlying) data included one who did not provide consent, one who was too impaired to proceed with any testing, one with visual problems, five who dropped out before completing all the background tests and at least two blocks of enumeration trials, and one VAD patient whose enumeration accuracy was 7.2 standard deviations worse than the overall mean and whose enumeration RT was 7.0 standard deviations longer than the overall mean. The lower numbers of VAD patients recruited may reflect the strict diagnostic criteria used, which excluded all 'mixed' diagnoses such as Alzheimer/Vascular dementia. Most patients (65\%) were taking prescribed medications including acetylcholinesterase inhibitors (e.g., donepezil) and selective serotonin reuptake inhibitors (e.g., citalopram).

In addition to the three groups of patients, 21 healthy controls over the age of 65 were recruited from an existing panel of older volunteers participating in aging research at the University of Warwick. They were selected to match the patients as closely as possible in terms of age and years of education. Some controls (24\%) were taking prescribed medications such as painkillers and sleeping tablets. The MMSE was used to check that controls reached levels expected for healthy aging; however, it was not possible to administer a complete battery of diagnostic tests to this group to exclude early signs of either dementia or depression (we return to this point in the General Discussion). There were no drop-outs during testing in the control group and all provided usable data. All participants were recruited on a voluntary basis and received no payment for taking part in the study.

Demographic information and background measures for the four experimental groups are summarized in Table 1 . The proportion of females was somewhat higher in the control group than in the patient groups; however, there were no effects of gender and no interactions involving gender in any of the analyses and so gender will not be considered 
further. Participants ranged in age between 65 and 88 years. Statistically, the groups were successfully matched for both age and education although the numerical trend for AD patients to be less well educated than controls is generally consistent with the literature (e.g., Fratiglioni \& Rocca, 2001; Ott et al., 1995). The groups were also similar in terms of reported current states of health and visual acuity.

There were group differences as expected on measures of depression (GDS-15; Sheikh \& Yesavage, 1986) and general cognitive status (MMSE; Folstein et al., 1975), with DEP patients impaired on the former and dementia patients impaired on the latter in comparison with controls. The MMSE scores of the dementia groups placed them in the mild stages of dementia, with those of the depressed patients and controls in the unimpaired range.

On the letter cancellation task, the two groups with dementia performed significantly worse than the other groups, although the deficits were mainly apparent in terms of accuracy for VAD patients and speed for AD patients. Importantly, there was no evidence of any participant missing targets in one particular region of visual space (i.e., no sign of visual neglect). The Trail Making Test (TMT; Reitan, 1958) revealed significant deficits in speed (TMT A) for AD patients and in executive functioning (TMT B-A) for both AD and VAD patients in comparison with those groups without dementia. ${ }^{1}$ Counting aloud was equally fast across the four groups and was error-free in all participants, thereby establishing that any mistakes in the enumeration task could not be attributed to an inability to count accurately.

Finally, although the DEP patients did not differ significantly from controls on any of the cognitive measures, they were numerically worse, consistent with previous demonstrations of cognitive deficits in depression (e.g., Baune, Suslow, Englelien, Arolt, \& Berger, 2006; Hartlage et al., 1993). 
Enumeration task. This was designed to use as little equipment as possible and to be mainly used in participants' homes. Thus, the experiment was conducted on a Sony Vaio laptop computer with a 1.73-GHz Pentium M processor and a 17-in. (43.2-cm) widescreen at a resolution of 1,440 x 900 pixels. The screen was placed approximately $60 \mathrm{~cm}$ away from the participant and at eye level. The participant's response key was the spacebar of the laptop keyboard while the experimenter entered the participant's numerical responses onto an externally connected Belkin numeric keypad.

The stimuli were filled black circles $\left(8 \mathrm{~mm}\right.$ diameter, $\left.0.76^{\circ}\right)$ appearing on a white background. Displays were generated by placing the stimuli randomly into the cells of an invisible 6 x 6 grid $\left(105 \times 105 \mathrm{~mm}, 10^{\circ} \times 10^{\circ}\right)$ with an interelement spacing of 82 pixels $\left(2^{\circ}\right)$. To disrupt any perception of a regular grid structure, each circle was displaced by \pm 1 10 pixels both horizontally and vertically. A typical display is illustrated in the top panel of Figure 1.

Each trial of the enumeration task consisted of a blank screen for 500 ms, a black central fixation cross $\left(4 \mathrm{~mm} \times 4 \mathrm{~mm}, 0.38^{\circ} \mathrm{x} 0.38^{\circ}\right)$ for $1,000 \mathrm{~ms}$, another blank screen for $500 \mathrm{~ms}$, and finally the display of between one and nine black circles, which remained until a response was made. The participant's task was to determine "how many dots are on the screen” as quickly as possible and respond by pressing the spacebar of the computer keyboard and saying aloud their numerical response. RT was measured from the onset of the enumeration display to the participant's press of the spacebar. ${ }^{2}$ The experimenter, who was seated in a position so that she could not see the computer screen, then entered the participant's response on the remote numeric keypad. This initiated the next trial, which also allowed the experimenter to insert occasional pauses in testing if necessary by delaying her entry of the participant's response. In addition, if the trial had been disrupted in any way (e.g., the participant turned to ask the experimenter a question, sneezed, pressed the spacebar 
before the circles had appeared, provided an invalid response such as " 10 ”, and so on), the experimenter pressed the “*” key instead, which recorded the trial as "invalid” and to be excluded from the analyses.

In pilot testing, it was found that some patients experienced difficulty in coordinating their manual and verbal responses (e.g., they said aloud their response but forgot to press the spacebar). Thus an alternative response method (as successfully used by Watson \& Humphreys, 1999, with neuropsychological patients) was offered to participants who were apparently struggling in the practice trials to comply with the standard method described above. This option allowed participants to make only a verbal response while the experimenter pressed the “+” key on the numeric keypad on their behalf at the same time (prior to entering the numeric response). This alternative method was used by a minority of participants in each group (9 AD; 1 VAD; 2 DEP; 2 CON). ${ }^{3}$ Although the experimenter's reaction time could introduce a small delay to these participants' responses, there was no reason to expect this delay to systematically vary as a function of numerosity, which is the focus of interest here. More importantly, it should be noted that all the analyses reported in the present article were conducted both with and without these participants' data and the results were essentially identical.

The task began with a block of 9 demonstration trials (1 for each numerosity, in a random order) during which the experimenter explained the task. When she was satisfied that the participant had understood the task requirements, a practice block of 18 trials ( 2 for each numerosity, in a random order) was administered. If necessary, this was repeated to ensure that the participant was comfortable with the procedure. This was followed by three experimental blocks, each of 45 trials (5 for each numerosity) presented in a random order. Between blocks of trials, participants could take short rest breaks; the next block proceeded only if they were willing to continue. 
Procedure. Ethical approval for the study (covering both Experiments 1 and 2) was obtained from the Coventry Research Ethics Committee of the UK National Research Ethics Service. The fourth author tested all participants individually in their own homes wherever possible and on inpatient wards or at the University when necessary. Sessions were conducted in quiet areas, free from distractions or disturbances and under appropriate illumination for each task. The experimenter first obtained the participant's informed consent. For patients who agreed to participate but were unable to give informed consent, a carer or guardian signed an assent form to sanction participation on the patient's behalf. Personal information (including education and health) was then obtained, followed by the background measures in the order as shown in Table 1, and finally the enumeration task was conducted.

Results and Discussion

All participants successfully completed three blocks of enumeration trials except for $3 \mathrm{AD}$ patients and 1 DEP patient who declined to continue after completing two blocks. These four patients were somewhat slower than average but otherwise their data were qualitatively similar to those of the other participants and so they were included in the analyses. Only $0.87 \%$ of trials were invalid overall. For each participant, the error rate and the mean correct RT were calculated separately for each numerosity; the overall means for each of the four groups are displayed in Figures 2 and 3, respectively. There was little evidence in any of the groups of speed-accuracy trade-offs as performance was both slower and less accurate for larger numerosities than for smaller numerosities.

For the statistical analyses, we adopted the usual procedure in enumeration studies of excluding the largest numerosity (in this case nine) because of possible contamination by end effects (see Mandler \& Shebo, 1982; Trick \& Pylyshyn, 1994). Thus RTs for the largest numerosity can be artificially lower because participants can be confident that there are no 
more remaining items to find as compared with the other numerosities. In all analyses of variance (ANOVAs) with a repeated measure, where there was evidence of departure from the sphericity assumption, we report Greenhouse-Geisser corrected values.

Errors. As shown in Figure 2, errors were rare in all groups for numerosities 1-4 but increased steadily thereafter and in a similar fashion across groups. These observations were confirmed by an ANOVA on the percentages of errors with group (4 levels: AD, VAD, DEP, and CON) as the between-subjects factor and numerosity (8 levels: 1-8) as the withinsubjects factor. There was a significant effect of numerosity, $F(3.2,183.1)=14.69, p<.001$, but no overall effect of group, $F<1$, and no interaction, $F<1$.

Response times. Focusing first on the RTs for AD patients and controls in Figure 3, the present data successfully replicated various aspects of our earlier results (Maylor et al., 2005) although the group differences were less dramatic. (However, it should be remembered that the present $\mathrm{AD}$ patients were at an earlier stage of the disease, with a mean MMSE score of 22.8 as compared with 17.3 previously.) Thus, the AD patients were slower overall than controls (1863 vs. $1422 \mathrm{~ms}$ ), subitizing $\operatorname{span}^{4}$ was smaller in AD patients compared to controls (2.54 vs. 3.24 items), and counting rate (obtained from linear regression over numerosities 5-8) was slower in AD patients than in controls ${ }^{5}$ (393 vs. 358 ms/item). In line with these observations, a 2 (group) x 8 (numerosity) mixed ANOVA confirmed a significant effect of group, $F(1,38)=10.06, p<.005$, and of numerosity, $F(2.4$, $90.7)=385.07, p<.001$, with a significant interaction between them, $F(2.4,90.7)=3.25, p$ $<$.05. Moreover, separate ANOVAs on the subitizing (1-3) and counting (5-8) ranges both produced significant interactions between group and numerosity, $F(1.4,53.4)=5.07, p<$ .05 , and $F(2.5,93.6)=3.56, p<.05$, respectively.

A striking feature of the AD group's data in Figure 3, however, is the abnormally long RT for numerosity 1 relative to numerosity 2, hereafter termed the "RT1>2” effect. 
This odd phenomenon raises the question of whether model-fitting to find the subitizing span (as described in Footnote 4) is appropriate in such circumstances as its presence could artifactually reduce span. It seems likely that this is the case here because the group by numerosity interaction in the subitizing range (1-3) was entirely due to larger group differences for numerosity 1, with the increase from RT2 to RT3 not significantly different for $\mathrm{AD}$ patients and controls (78 and $64 \mathrm{~ms}$, respectively) and both within the traditional subitizing rate of $<100 \mathrm{~ms} /$ item.

Maylor et al. (2005) also observed an RT1>2 effect in their AD patients but in that case it did not negate their conclusion that subitizing span was reduced by AD for a number of reasons. For example, the increase from RT2 to RT3 was significantly greater for their AD patients than for controls (373 and 72 ms/item, respectively). We can therefore conclude that subitizing span is significantly reduced in AD patients in comparison with controls in the later stages of the disease (Maylor et al., 2005) but probably not in the earlier stages (present study). However, counting rate is significantly slower and the RT1>2 effect significantly greater in AD patients than in controls at both mild and moderate stages of the disease.

In studies of visual enumeration in normal aging, a numerical RT1 $>2$ effect has often been observed in older adults but never in young adults (Watson et al., 2002, 2005a, 2005b). Here, it was apparent in a majority of participants in all four groups (18/19 AD; 4/6 VAD; 10/15 DEP; 15/21 CON). Figure 4 illustrates the effects more clearly as mean differences between RT1 and RT2 for each group (i.e., RT2 minus RT1, which is negative for the RT1>2 effect); for comparison purposes, data are also presented from 17 undergraduate students at the University of Warwick (12 females, 5 males; mean age $=19.4$ years). Note that although the RT1 $>2$ effect was strongest in the AD group, $t(18)=3.64, p<.005$, smaller 
trends were also evident in both the VAD group, $t(5)=2.05, p<.1$, and the controls, $t(20)=$ $1.88, p<.08$, with the opposite trend for the young group, $t(16)=2.10, p=.05$.

It could be argued that despite demonstration and practice blocks of trials, older participants may still take longer to grasp the parameters of the task and to appreciate that " 1 ” is a legitimate response when asked to "count" the stimuli in an enumeration task. To explore this possibility, the data were split into the three blocks of experimental trials and plotted in Figure 5 for the two groups with the largest RT1>2 effects, namely, AD patients ${ }^{6}$ and controls. As can be seen, there was little evidence that the effect decreased with practice.

Finally, turning to the remaining two groups in Experiment 2, overall RTs for VAD and DEP patients were 1547 and 1453 ms, respectively, their subitizing spans were 3.31 and 3.42 items, and their counting (5-8) rates were 387 and $336 \mathrm{~ms} / \mathrm{item}$. As can be seen from Figure 3, both VAD and DEP patients resembled controls at smaller numerosities but VAD patients fell between AD patients and controls at larger numerosities because of their slower counting rate, which resembled that of $\mathrm{AD}$ patients. A 4 (group) x 8 (numerosity) mixed ANOVA showed a significant effect of group, $F(3,57)=4.60, p<.01$, and of numerosity, $F(2.4,139.4)=539.78, p<.001$, with a significant interaction between them, $F(7.3,139.4)=$ 2.46, $p<.02$. Post hoc tests (Tukey HSD) on the overall group effect revealed two significant differences $(p<.05)$ : AD vs. DEP, and AD vs. CON. (As already mentioned, these group differences remained significant when those who did not press the spacebar themselves were excluded.) The smaller $(n=6)$ group of VAD patients did not differ significantly from any of the other groups. An additional ANOVA on the counting (5-8) range of numerosities to compare dementing and nondementing participants confirmed a significantly slower counting rate in the former ( $\mathrm{AD}$ and VAD patients) than in the latter (DEP patients and controls), with a significant dementia x numerosity interaction, $F(2.6$, 156.1) $=3.39, p<.05$. 
In summary, it is clear from the results of Experiment 1 that although a true reduction in subitizing span probably does not occur until the later stages of AD (Maylor et al., 2005), at least some enumeration deficits are evident even in the early stages of the disease in comparison with controls (e.g., longer overall RT; slower counting rate). However, these are not specific to AD because, for example, counting rate is similarly slowed by VAD (though, interestingly, not by depression). Before discussing more general implications of these findings, we report a follow-up experiment designed to investigate further the intriguing RT1>2 effect, which was significantly larger in AD patients than in any other group.

\section{Experiment 2}

In Experiment 2, we returned to test as many of the participants in the $\mathrm{AD}$ and control groups of Experiment 1 as possible. Our first aim was to establish the robustness of the RT1>2 effect by asking participants to complete three more blocks of standard enumeration trials.

A second aim was to examine whether the RT1>2 effect would occur when the task was to enumerate targets (Os) that appeared along with distractors (Xs) that had to be ignored (see middle panel of Figure 1). Our reasoning was that a single item appearing in an otherwise empty visual field may be especially powerful in capturing and holding attention such that it is then more difficult to disengage from it to check for other potential targets. This might be particularly problematic for AD patients who are known to show abnormal spatial orienting and to have problems with attentional disengagement (e.g., Parasuraman, Greenwood, Haxby, \& Grady, 1992; Tales, Snowden, Brown, \& Wilcock, 2006). However, with additional distractors present, this should not occur because even in the case of a single target, there are other stimuli present. Accordingly, the group difference in the RT1>2 effect should be reduced. 
The third task required the enumeration of 1-6 items that were described and presented as dots on a die (see lower panel of Figure 1). This traditionally results in a flat RT-numerosity function (e.g., Mandler \& Shebo, 1982) because the highly familiar arrangements of dots allow the task to be performed via pattern recognition rather than enumeration. We supposed that at least in the early stages of the disease, AD patients would be able to switch to a pattern recognition strategy when given the opportunity. Thus, our prediction was that the RT1>2 effect, if specific to enumeration, would be abolished in this task for both $\mathrm{AD}$ patients and controls.

Lastly, we included a visual search task in which participants determined whether or not there was a single target $(\mathrm{O})$ present among multiple distractors (Xs). The aim was to test the possibility that slow (perhaps overly cautious) participants may be particularly reluctant to acknowledge that there is only one item when enumerating because of rechecking, an effect akin to the observation in both older adults and AD patients that the time to decide that a target is absent in visual search tasks can be abnormally long (e.g., Plude \& DoussardRoosevelt, 1989; single-feature condition of Tales et al., 2002). This fourth task also allows a direct comparison between enumeration of, and search for, single-feature-defined targets among distractors (cf. Watson et al., 2002).

Method

Participants. Eleven of the 19 AD patients and 18 of the 21 controls from Experiment 1 agreed to take part in Experiment 2, which was conducted after an average interval of 3 months. All 29 participants provided data that were included in the final analyses. Demographic information and background measures collected during Experiment 1 for the two groups are presented in Table 2. Despite participant attrition, the groups remained well matched in terms of age, self-rated health, visual acuity, and depression; however, the numerically similar superiority in education for controls over AD patients now 
reached significance. The AD group remained significantly impaired on measures of cognition (MMSE, letter cancellation speed, and TMT). Note that only the GDS-15 and MMSE background tests were readministered in Experiment 2, with almost identical results in both groups (see scores in parentheses in Table 2).

Enumeration and search tasks. The same equipment and general set-up were used as in Experiment 1. As before, the majority of participants in each group (9/11 AD patients; 18/18 controls) responded by pressing the spacebar of the computer keyboard while vocalizing their responses, whereas for the remaining two participants, the experimenter pressed a key on the numeric keypad coincidentally with their vocal responses.

For the replication of Experiment 1, the stimuli were again filled black circles. The stimuli for the enumeration of Os among Xs and visual search tasks were black letters, with a line width of $1 \mathrm{~mm}$, appearing on a white screen. They were positioned on the screen in the same way as described for the enumeration task of Experiment 1. Targets (Os) were the same size as before (i.e., $8 \mathrm{~mm}$ diameter, $0.76^{\circ}$ ) whereas distractors (Xs) were 7 x $6 \mathrm{~mm}$ $\left(0.67^{\circ} \times 0.57^{\circ}\right)$. For ease of exposition, we will refer hereafter to the first two tasks as the enumeration of Os and the enumeration of Os among Xs although the targets were filled and unfilled Os, respectively, as illustrated in the upper and middle panels of Figure 1. [Note that in previous studies with both young and older adults, we have never observed any qualitative differences between the enumeration of filled vs. unfilled circles - e.g., compare Watson, Maylor, Allen, and Bruce (2007) and Watson et al. (2005b).] For the dots-on-a-die task, filled white circles ( $8 \mathrm{~mm}$ diameter, $\left.0.76^{\circ}\right)$ appeared on a black square $\left(82 \times 82 \mathrm{~mm}, 7.82^{\circ} \mathrm{x}\right.$ $7.82^{\circ}$ ) with rounded corners to resemble a die (see lower panel of Figure 1). In this case only, the dots were placed exactly in 1-6 positions of a 3 x 3 grid (i.e., with no small random displacements to disrupt regularity). The arrangements for each numerosity were as follows: 1 = central position; 2 = top-right and bottom-left positions; 3 = top-right, central, and 
bottom-left positions; 4 = top-left, top-right, bottom-left, and bottom-right positions; 5 = topleft, top-right, central, bottom-left, and bottom-right positions; 6 = top-left, top-right, centralleft, central-right, bottom-left, and bottom-right positions.

The enumeration of Os task was identical to that of Experiment 1, with a demonstration block, a practice block, and three experimental blocks of trials. In the enumeration of Os among Xs task, in addition to 1-9 target Os, there were also 19-11 distractor Xs, respectively, making a total of 20 items displayed on every trial. Participants were required to determine the number of Os present and to "ignore the Xs". The enumeration of dots on a die task was similar to the standard enumeration task except that (i) participants were asked "how many dots are on the die", and (ii) there were fewer trials per block because of only 6 numerosities rather than 9. As in Experiment 1, there was a maximum of 15 experimental trials per numerosity contributing to the means for each participant in all three enumeration tasks. In the visual search task, participants were required to search displays of 5, 10, or $20 \mathrm{X}$ distractors and to indicate the presence or absence of a single target O by pressing the spacebar and saying “yes” or "no”, respectively. The target was present on half of the trials and took the place of one of the distractors. Over three experimental blocks of visual search, there were 18 trials for each combination of target present or absent and display size, presented in random order. These were preceded by demonstration and practice blocks with 1 and 2 trials, respectively, for each target $\mathrm{x}$ display size combination.

Procedure. Testing was conducted by the same experimenter and under the same conditions as in Experiment 1. However, for $2 \mathrm{AD}$ patients and 2 controls, data collection had to be split over two visits conducted within two weeks of each other. After consent/assent was obtained, the tasks were carried out in the following order: GDS-15, 
MMSE, enumeration of Os, enumeration of Os among Xs, visual search, and enumeration of dots on a die.

\section{Results and Discussion}

All participants successfully completed three blocks of trials for each of the four tasks in Experiment 2 with the exception of one AD patient who was unable to grasp the requirements of the visual search task despite repeated practice blocks and so it was aborted. Less than $1 \%$ of trials were invalid $(0.49 \%$ for enumeration of Os, $0.95 \%$ for enumeration of Os among Xs, $0.88 \%$ for die enumeration, and $0.79 \%$ for visual search).

Enumeration of Os alone and Os among Xs. The mean percentage error rates and correct RTs are plotted for numerosities 1-9 in Figures 6 and 7, respectively. Note again the absence of any speed-accuracy trade-offs in that performance was both slower and less accurate (i) with increasing numerosity in both groups of participants, (ii) with distractors (Xs) than without, and (iii) in AD patients than in controls. For errors (Figure 6), there was an unexpected peak at numerosity 5 in the AD group but this was largely due to one patient. A 2 (group) x 2 (distractors: absent vs. present) x 8 (numerosity) mixed ANOVA on error rates revealed no overall difference between $\mathrm{AD}$ patients and controls, $F<1$, but significantly more errors with distractors than without, $F(1,27)=7.48, p<.02$, and significantly more errors for larger numerosities, $F(2.3,61.1)=13.21, p<.001$. A marginal interaction between group and distractors, $F(1,27)=3.23, p<.09$, suggested a tendency for AD patients to be more impaired by distractors (2.7\% errors without distractors vs. $5.7 \%$ errors with distractors) than controls (2.9\% vs. 3.5\%), with $p>.3$ for the remaining interactions. $^{7}$

There are several features to note from the RTs in Figure 7. Focusing first on the replication of Experiment 1 shown by the solid lines, it can be seen that the general pattern was successfully reproduced: AD patients were slower overall than controls (1875 vs. 1316 
ms), subitizing span (from bilinear modeling to obtain the flex point - see Footnote 4) was smaller in AD patients compared with controls (2.71 vs. 3.34 items), and counting rate (5-8) was slower in AD patients than in controls (412 vs. 374 ms/item). In addition, the increase from RT2 to RT3 was small and very similar in AD patients and controls (36 and 43 ms, respectively) suggesting that the apparently reduced subitizing span in early stage AD patients is an artifact of a greater RT1-2 effect in AD patients than in controls, as in Experiment 1. Again, this effect is shown more clearly by mean RT differences (see the leftmost bars of Figure 8).

The second comparison of interest in Figure 7 is between enumeration with and without distractors for the control group, which successfully replicates the results of Watson et al. (2002). Using the same tasks, they found that, whereas subitizing was unaffected by the presence of distractors in young adults, it was significantly less evident with distractors than without in older adults (see also Sliwinski, 1997). The same is true of the older adult controls in the present study (and also of the $\mathrm{AD}$ patients), with a significantly greater increase for controls from RT2 to RT3 with distractors $(140 \mathrm{~ms}$, which exceeds the traditional subitizing rate of $100 \mathrm{~ms} /$ item) than without (43 ms), $p<.005$. (For comparison, a group of four undergraduate students who completed the tasks of Experiment 2 produced mean increases of approximately 30 ms from RT1 to RT2 and from RT2 to RT3, both with and without distractors.)

The third point to highlight from Figure 7 is that the presence of distractors had little effect on the rate of counting in either group as shown by approximately parallel functions with and without distractors for larger numerosities. Again, this replicates Watson et al.’s (2002) findings in both young and older adults. However, the overall impact of distractors on RTs can be seen from Figure 7 to be twice as large for AD patients as for controls, with mean increases (from solid to dashed lines) of 704 and 352 ms, respectively. Similarly, older 
adults are more disrupted overall than are young adults by the presence of distractors while enumerating (Watson et al., 2002, 2005a, 2005b), consistent with both dementia- and agerelated deficits in ignoring irrelevant information (e.g., Amieva et al., 2004; Hasher, Zacks, \& May, 1999; Levinoff, Li, Murtha, \& Chertkow, 2004; see Watson et al., 2005a, 2005b, for discussion).

Finally, and most crucially, although the RT1>2 effect was reduced in AD patients by the presence of distractors as a result of less subitizing (see Figure 7), AD patients were still relatively slow to respond to numerosity 1 in comparison with controls as shown by the central bars of Figure 8. Thus the group difference in RT2 minus RT1 remained at least as large for enumerating Os among Xs as for enumerating Os alone.

The above observations were confirmed by two ANOVAs on mean correct RTs with group (AD patients vs. controls) as the between-subjects factor, and distractors (absent vs. present) and numerosity (5-8 in the first case; 1-3 in the second case) as within-subjects factors. For the counting range (5-8), there were significant effects of group, $F(1,27)=6.48$, $p<.02$, distractors, $F(1,27)=116.56, p<.001$, and numerosity, $F(2.0,54.3)=220.19, p<$ .001. There was also an interaction between group and distractors, $F(1,27)=10.10, p<$ .005 , but the interaction between group and numerosity failed to reach significance, $F(2.0$, $54.3)=2.31, p=.11$, with $F<1$ for the remaining interactions. For the subitizing range (13 ), there were significant effects of group, $F(1,27)=10.33, p<.005$, distractors, $F(1,27)=$ 44.36, $p<.001$, and numerosity, $F(1.7,45.9)=18.27, p<.001$. In addition, there were interactions between group and distractors, $F(1,27)=6.60, p<.02$, between group and numerosity, $F(1.7,45.9)=5.05, p<.02$, and between distractors and numerosity, $F(1.7$, $47.1)=18.81, p<.001$, with no 3-way interaction, $F<1$. Note that exactly the same pattern of significant effects was obtained when numerosities 1-2 were analyzed rather than 1-3. 
Enumeration of dots on a die. Only two errors were made in this task, one by an AD patient and one by a control. From the mean correct RTs in Figure 9, it can be seen that although AD patients were somewhat slower overall than controls (766 and 517 ms, respectively), ${ }^{8}$ neither group showed much change in RT with increasing numerosity from 16. Moreover, the RT1>2 effect was completely abolished in both groups (see right-most bars of Figure 8). A mixed 2 (group) x 5 (numerosity) ANOVA revealed a significant effect of group, $F(1,27)=6.11, p<.05$. The effect of numerosity also reached significance, $F(3.1$, $82.7)=4.17, p<.01$, as a result of slightly but consistently longer RTs to numerosity 5 than to numerosities 1-4 in both groups ( $F<1$ for the interaction).

Visual search for O among Xs. Errors were rare in both AD patients (0.74\%) and controls (0.51\%) and were therefore not analyzed further. Mean correct RTs for target absent and present trials as a function of display size are shown in Figure 10 for AD patients and controls. A 2 x 2 x 3 (Group x Target x Display Size) mixed ANOVA revealed that AD patients were slower overall than controls (1109 and $690 \mathrm{~ms}$, respectively), $F(1,26)=12.93$, $p<.002$, and that RTs were longer on absent than on present trials, $F(1,26)=17.16, p<$ .001 . The main effect of display size reached significance, $F(1.3,33.3)=5.95, p<.02$. However, search slopes were below $10 \mathrm{~ms} /$ item, which is typically taken to indicate spatially parallel search, averaging 4.4 (absent) and 1.5 (present) ms/item for AD patients, and 3.5 and $1.4 \mathrm{~ms} /$ item for controls. There were no significant interactions although the Group $\mathrm{x}$ Target interaction approached significance, $F(1,26)=3.18, p<.09$, indicating a trend for the group difference to be somewhat greater for absent than for present trials (cf. Tales et al., 2002).

For each participant, the mean RT difference between absent and present trials was calculated as a measure of response caution/rechecking. Contrary to prediction, there were no significant correlations between this measure and the RT1>2 effect for enumerating Os alone or Os among Xs for either AD patients or controls (all p’s > .57), except for that 
between absent minus present RT and RT2 minus RT1 for enumerating Os among Xs for controls, $r(17)=.55, p<.02$, which is actually opposite to prediction (i.e., controls who were slower to respond absent showed a smaller RT1>2 effect).

Summarizing the main findings from Experiment 2, the robustness of the RT1>2 effect was demonstrated by its persistence across three further blocks of standard enumeration trials; the effect also remained significantly larger in $\mathrm{AD}$ patients than in controls. When distractors were added, subitizing (though not counting) was impaired in both groups, as expected from previous studies of enumeration in older adults (Watson et al., 2002; Watson, Maylor, Allen, \& Bruce, 2007). Note, however, that this was despite both groups showing efficient “pop-out” visual search for the same stimuli, which runs counter to predictions from FINST theory (Trick \& Pylyshyn, 1994). The FINST mechanism operates on the outputs of preattentive processing so when there are distractors present in the visual field, subitizing of the target items should be possible if they can be individuated at a preattentive level - in other words, if they can be detected efficiently in a spatially parallel manner across the visual field as evidenced by a flat visual search function. The present results therefore provide further support for the suggestion that pop-out may be necessary but not always sufficient for subitizing to occur (see Watson et al., 2002, and Watson, Maylor, Allen, \& Bruce, 2007, for an explanation in terms of a modified FINST account). More importantly here, the AD patients' relative difficulty with numerosity 1 was not reduced by the addition of distractors, thereby discounting an explanation in terms of problems associated with attention capture by, and/or subsequent disengagement from, a single item appearing in an otherwise empty visual field. We can also rule out any association between the reluctance to respond absent in visual search (perhaps because of rechecking) and the relatively slow acknowledgment of only one item in enumeration. On the other hand, the RT1>2 effect was completely abolished in both groups when 
enumerating dots on a die. From the almost flat RT-numerosity functions, it can be concluded that this task was accomplished by recognizing the familiar canonical patterns rather than by enumerating (subitizing/counting) the dots. Thus the RT1 $>2$ effect appears to be specific to enumeration.

\section{General Discussion}

\section{Summary of Results}

Maylor et al. (2005) reported that speeded visual enumeration appeared to show distinct qualitative differences between the effects of normal aging and moderate-stage AD on performance, thereby raising the task's potential as a diagnostic and/or screening tool for dementia. The first main objective of the present study was therefore to establish whether these enumeration deficits could be reproduced in mild-stage (newly diagnosed) AD patients. As in the earlier study, the AD group in Experiment 1 showed significant deficits in comparison with age-matched controls - they were slower overall, with a slower rate of counting - although the differences were smaller and there was greater overlap between the two groups than before. Subitizing span appeared again to be reduced by AD but in the present case this was an artifact of unusually long RTs for numerosity 1 (RT1>2 effect), which was particularly marked in $\mathrm{AD}$ patients. Together, the two studies suggest that while some enumeration deficits are apparent in both earlier and (to a greater extent) later stages of $\mathrm{AD}$ (e.g., slower counting rate), others are truly apparent only in later stages (i.e., reduced subitizing span). Our second main question was whether enumeration deficits also occur in patients with other late life psychiatric syndromes, namely, VAD and depression. VAD patients produced a similar counting rate to that of AD patients and did not differ reliably from them overall; in contrast, the depressed patients' enumeration performance was indistinguishable from that of the controls. While we therefore have to conclude that enumeration deficits are not specific to $\mathrm{AD}$, it remains possible that they may nevertheless 
distinguish dementing from nondementing older adults (although it should be emphasized that these are group results). Experiment 2 aimed to follow up the RT1 $>2$ effect observed in AD patients but also to a lesser extent in controls (and VAD patients). The effect was unrelated to response criterion in visual search and it did not occur for familiar configurations enabling pattern recognition. However, AD patients continued to show relatively long RTs to numerosity 1 in comparison with controls when enumerating random items both with and without distractors. This unexpected RT1>2 effect cannot be explained by any of the current models of enumeration, including the FINST account, all of which predict monotonic RT-numerosity functions.

\section{Counting Rate Deficits}

Considering first the enumeration of larger numerosities (5-8), we have argued elsewhere that, contrary to age-related general slowing, counting rate is spared by normal aging because the rate-limiting processes of planning and executing eye movements are unaffected (see Maylor \& Watson, 2005; Watson et al., 2005a, 2005b). Why then might counting rate be slowed by dementia? As mentioned in the Introduction, enumerating beyond the subitizing range involves the coordination of several complex operations at least some of which are known to be impaired in dementia such as the disengagement and shifting of visuospatial attention from one item to another (e.g., Parasuraman et al., 1992; Parasuraman \& Haxby, 1993; Rizzo, Anderson, Dawson, Myers, \& Ball, 2000; Rösler, Mapstone, Hays-Wicklund, Gitelman, \& Weintraub, 2005; Tales et al., 2006), saccadic eye movements (e.g., Fletcher \& Sharpe, 1986), and inhibitory/executive functioning (e.g., Amieva et al., 2004; Perry \& Hodges, 1999). Also, working memory is required to keep track of which items have been counted (see Tuholski, Engle, \& Baylis, 2001, for evidence of slower counting rates for participants with lower working memory spans) and AD in particular is associated with a decline in working memory capacity (e.g., Baddeley, Bressi, 
Della Sala, Logie, \& Spinnler, 1991; Baddeley, Logie, Bressi, Della Sala, \& Spinnler, 1986; Belleville, Peretz, \& Malenfant, 1996; Collette, Van der Linden, Bechet, Belleville, \& Salmon, 1998).

In view of these complex requirements, it would not be surprising to find slower counting rates in other cognitively impaired or dementing groups. Indeed, a recent study by Halpern, Clark, Moore, Cross, and Grossman (2007) compared patients with corticobasal degeneration (CBD), patients with frontotemporal dementia (FTD) and age-matched controls ( $~ 70$ years of age) on a related task in which participants determined whether or not the number of dots presented (1-9) matched a single Arabic numeral displayed immediately below the dots. From their Figure 1, it appears that the RT-numerosity slope over the counting range (5-8) for controls was approximately the same as for controls in the present study whereas the slope was twice as steep for the FTD patients and four times as steep for CBD patients (who were also less accurate). Thus it seems that although counting rate is unaffected by normal aging, it is slowed in at least four groups showing abnormal aging, namely, AD, VAD, CBD, and FTD patients. Although it is difficult to make direct comparisons across the two studies, it would appear that counting deficits may be somewhat greater in $\mathrm{CBD}$ and FTD patients than in $\mathrm{AD}$ and VAD patients, despite comparable mean MMSE scores ( 22 in Halpern et al.’s study; 23 here). Further work using the same paradigm in all groups would be required to confirm this.

In striking contrast to dementia, depression produced no enumeration deficits in the present study, thus bringing together for the first time previous preliminary observations of no effects of depression in either the subitizing or counting ranges of numerosity (see, respectively, Nebes et al., 1992, and Lee et al., 2000). This finding is of interest because the distinction between dementia and depression is a notorious diagnostic trap. Those neuropsychological deficits known to best predict incident dementia among normal older 
people, especially the TMT and word list learning (Chen et al., 2001), are also found among older people with depression (Elderkin-Thompson, Mintz, Haroon, Lavretsky, \& Kumar, 2006; Rocca et al., 2005). Further work is needed to establish whether enumeration deficits can prospectively distinguish organic (dementia) cases from non-organic (depression; normal older people) cases.

\section{Subitizing Span and the RT1>2 Effect}

Turning to the enumeration of smaller numerosities (1-3), the present study appeared to extend Maylor et al.’s (2005) demonstration of reduced subitizing span in AD to an earlier stage of the disease (MMSE of 23 as opposed to 17). However, in this case (though not in the previous study), the reduction was entirely attributable to unusually slow responses to numerosity 1, evident in a majority of participants but especially in $\mathrm{AD}$ patients. At the very least, the presence of an RT1>2 effect suggests that some caution is needed when applying the standard method of bilinear modeling to obtain an estimate of subitizing span. For such nonmonotonic RT-numerosity functions as observed here, it is clearly inappropriate and can produce misleadingly small spans. To our knowledge, in over 100 years of research on the enumeration task, an RT1 >2 effect has rarely been mentioned. As already noted, older adults often show a numerical trend for RT1>2 (Watson et al., 2002, 2005a, 2005b), which actually reached significance in Experiment 1 of Watson et al. (2005a). In young adults, Trick and Enns (1997) observed a “completely unforeseen” (p. 190) nonmonotonic RT-numerosity function for 10/16 participants in 1/18 tasks requiring the enumeration of targets among distractors, which they concluded was "beyond the power of any...present theories of enumeration, or for that matter, any theory of preattention” (p. 193). Interestingly, Halpern et al. (2007) "excluded arrays of 1 dot from [their] analyses in order to minimize confusion that seemed to emerge in patients with these stimuli” (p. 146). 
Nonetheless, there are several possibilities for this effect that would be worthy of additional exploration. One is that the context of the task might influence whether a slow response to numerosity 1 occurs. In the present study, when asked to enumerate the dots on a die, the AD group may have viewed the context of the task in a different way to the more abstract and less familiar task of enumerating randomly placed dots. The familiarity with this type of common stimulus and context of interpreting it as a die may have rendered patients more willing to respond " 1 ” as this would be a highly practiced response in this context.

It is also possible that the contrast reflects differences in attentional capture by objects and their parts. It has long been proposed that visual attention might be object- as opposed to space-based (e.g., Duncan, 1984). In this sense, a die would consist of a single object that contains a number of features or a texture (i.e., the dots). It could be that when presented as a feature within a single object, a lone dot is less likely to capture and hold attention compared to presenting isolated dots, which are more likely to be treated as individual objects and thus perhaps capture and hold attention to a greater degree. The boundaries of the die also provided a clear constraint to the area in which the dots could fall, unlike in the random dot conditions in which the stimuli were presented against an essentially unbounded blank screen. This additional cue as to where the dots might fall could have encouraged the AD patients to be more confident in responding " 1 ” than when the display area was less certain. In conclusion, it seems that further research will probably be necessary to fully account for participants’ difficulty in enumerating one randomly positioned target item, which will probably require alternative methods such as eye movement monitoring (cf. Watson et al., 2005b).

Limitations of the Present Study

Finally, some possible limitations of the present study need to be addressed. Most obviously, there were few VAD patients $(n=6)$ in comparison with the other patient groups 
in Experiment 1 (19 AD and 15 depressed patients). Nonetheless, the data they provided were sufficient to answer the critical question of whether enumeration deficits are specific to $\mathrm{AD}$ as counting rate was similarly slowed in newly diagnosed $\mathrm{AD}$ and VAD patients relative to age-matched controls. Another major issue common to studies of dementia concerns the difficulties outlined in the Introduction associated with diagnosing patients. Thus, despite applying standard procedures and criteria, it remains a possibility that some patients were incorrectly diagnosed. It is also possible that not all participants in the control group may have been free from dementia. For example, some apparently healthy controls may have been in the preclinical stage of AD (for discussion of this problem, see Bäckman, Small, \& Fratiglioni, 2004; Sliwinski, Hofer, Hall, Buschke, \& Lipton, 2003). Indeed, one control participant in Experiment 1 produced enumeration data that more closely resembled those of the AD group than of the control group. He had the lowest MMSE score of the controls (26) and also performed very poorly on the TMT Part B. It should therefore be acknowledged that the present effects may be underestimates of the true group differences because of possible misclassifications.

\section{Conclusions}

Overall, the present study has shown that enumeration deficits occur in early as well as in later stages of $\mathrm{AD}$ but they are not specific to $\mathrm{AD}$ because they also occur in $\mathrm{VAD}$, though not in depression. We therefore have to conclude that although this simple test of enumeration reveals group differences between dementing and nondementing older people, it is unlikely to reliably differentiate early $\mathrm{AD}$ from other pathological conditions of old age. In addition, the enumeration data of $\mathrm{AD}$ patients in particular reveal a striking and unexpected feature, namely, the unusually slow enumeration of one item, which cannot be explained by any existing model of visual enumeration and is thus worthy of further investigation. 


\section{References}

Albert, M. S. (2008). The neuropsychology of the development of Alzheimer's disease. In F. I. M. Craik and T. A. Salthouse (Eds.), The handbook of aging and cognition ( ${ }^{\text {rd }}$ ed., pp. 97-132). New York: Psychology Press.

American Psychiatric Association. (1994). Diagnostic and statistical manual of mental disorders ( $4^{\text {th }}$ ed.). Washington, DC: Author.

Amieva, H., Phillips, L. H., Della Sala, S., \& Henry, J. D. (2004). Inhibitory functioning in Alzheimer’s disease. Brain, 127, 949-964.

Bäckman, L., Small, B. J., \& Fratiglioni, L. (2004). Cognitive deficits in preclinical Alzheimer’s disease: Current knowledge and future directions. In R. A. Dixon, L. Bäckman and L.-G. Nilsson (Eds.), New frontiers in cognitive aging (pp. 161-177). Oxford: Oxford University Press.

Baddeley, A. D., Bressi, S., Della Sala, S., Logie, R., \& Spinnler, H. (1991). The decline of working memory in Alzheimer’s disease: A longitudinal study. Brain, 114, 2521-2542.

Baddeley, A., Logie, R., Bressi, S., Della Sala, S., \& Spinnler, H. (1986). Dementia and working memory. Quarterly Journal of Experimental Psychology, 38A, 603-618.

Basak, C., \& Verhaeghen, P. (2003). Subitizing speed, subitizing range, counting speed, the Stroop effect, and aging: Capacity differences and speed equivalence. Psychology and Aging, 18, 240-249.

Baune, B. T., Suslow, T., Engelien, A., Arolt, V., \& Berger, K. (2006). The association between depressive mood and cognitive performance in an elderly general population the MEMO study. Dementia and Geriatric Cognitive Disorders, 22, 142-149.

Belleville, S., Peretz, I., \& Malenfant, D. (1996). Examination of the working memory components in normal aging and in dementia of the Alzheimer type. Neuropsychologia, 34, 195-207. 
Birren, J. E. (1965). Age changes in speed of behavior: Its central nature and physiological correlates. In A. T. Welford \& J. E. Birren (Eds.), Behavior, aging and the nervous system (pp. 191-216). Springfield, IL: Charles C Thomas.

Boone, K. B., Lu, P., Back, C., King, C., Lee, A., Philpott, L., Shamieh, E., \& WarnerChacon, K. (2002). Sensitivity and specificity of the Rey Dot Counting Test in patients with suspect effort and various clinical samples. Archives of Clinical Neuropsychology, 17, 625-642.

Cerella, J., Poon, L. W., \& Williams, D. (1980). Age and the complexity hypothesis. In L. W. Poon (Ed.), Aging in the 1980s (pp. 332-340). Washington, DC: American Psychological Association.

Chen, P. J., Ratcliff, G., Belle, S. H., Cauley, J. A., DeKosky, S. T., \& Ganguli, M. (2001). Patterns of cognitive decline in presymptomatic Alzheimer disease: A prospective community study. Archives of General Psychiatry, 58, 853-858.

Collette, F., Van der Linden, M., Bechet, S., Belleville, S., \& Salmon, E. (1998). Working memory deficits in Alzheimer’s disease. Brain and Cognition, 37, 147-149.

Corrigan, J. D., Hinkeldey, M. S. (1987). Relationships between Parts A and B of the Trail Making Test. Journal of Clinical Psychology, 43, 402-409.

Dehaene, S., \& Cohen, L. (1994). Dissociable mechanisms of subitizing and counting: Neuropsychological evidence from simultanagnosic patients. Journal of Experimental Psychology: Human Perception and Performance, 20, 958-975.

Delazer, M., Karner, E., Proell, S., \& Benke, T. (2006). Counting complex dot patterns in Alzheimer’s disease. Journal of Clinical and Experimental Neuropsychology, 28, 721731.

Desmond, D. W. (2004). The neuropsychology of vascular cognitive impairment: Is there a specific cognitive deficit? Journal of the Neurological Sciences, 226, 3-7. 
Duncan, J. (1984). Selective attention and the organization of visual information. Journal of Experimental Psychology: General, 113, 501-517.

Elderkin-Thompson, V., Mintz, J., Haroon, E., Lavretsky, H., \& Kumar, A. (2006).

Executive dysfunction and memory in older patients with major and minor depression. Archives of Clinical Neuropsychology, 21, 669-676.

Fletcher, W. A., \& Sharpe, J. A. (1986). Saccadic eye movement dysfunction in Alzheimer’s disease. Annals of Neurology, 20, 464-471.

Folstein, M. F., Folstein, S. F., \& McHugh, P. R. (1975). “Mini-Mental State”: A practical method for grading the cognitive state of patients for the clinician. Journal of Psychiatric Research, 12, 189-198.

Foster, J. K., Behrmann, M., \& Stuss, D. T. (1999). Visual attention deficits in Alzheimer's disease: Simple versus conjoined feature search. Neuropsychology, 13, 223-245.

Fratiglioni, L., \& Rocca, W. A. (2001). Epidemiology of dementia. In F. Boller and S. F. Cappa (Eds.), Handbook of neuropsychology, $2^{\text {nd }}$ edition, Volume 6 (pp. 193-215). Amsterdam: Elsevier.

Fujimori, M., Imamura, T., Yamashita, H., Hirono, N., \& Mori, E. (1997). The disturbances of object vision and spatial vision in Alzheimer's disease. Dementia and Geriatric Cognitive Disorders, 8, 228-231.

Gallistel, C. R., \& Gelman, R. (1992). Preverbal and verbal counting and computation. Cognition, 44, 43-74.

Graham, N. L., Emery, T., \& Hodges, J. R. (2004). Distinctive cognitive profiles in Alzheimer’s disease and subcortical vascular dementia. Journal of Neurology, Neurosurgery and Psychiatry, 75, 61-71. 
Halpern, C., Clark, R., Moore, P., Cross, K., \& Grossman, M. (2007). Too much to count on: Impaired very small numbers in corticobasal degeneration. Brain and Cognition, 64, 144-149.

Halpern, C., McMillan, C., Moore, P., Dennis, K., \& Grossman, M. (2003). Calculation impairment in neurodegenerative diseases. Journal of the Neurological Sciences, 208, 31-38.

Hartlage, S., Alloy, L. B., Vazquez, C., \& Dykman, B. (1993). Automatic and effortful processing in depression. Psychological Bulletin, 113, 247-278.

Hasher, L., Zacks, R. T., \& May, C. P. (1999). Inhibitory control, circadian arousal, and age. In D. Gopher \& A. Koriat (Eds.), Attention and performance XVII. Cognitive regulation and performance: Interaction of theory and application (pp. 653-675). Cambridge, MA: MIT Press.

Hebert, L. E., Scherr, P. A., Bienias, J. L., Bennett, D. A., \& Evans, D. A. (2003). Alzheimer disease in the US population: Prevalence estimates using the 2000 census. Archives of Neurology, 60, 1119-1122.

Hofman, A., Rocca, W. A., Brayne, C., Breteler, M. M. B., Clarke, M., Cooper, B. et al. (1991). The prevalence of dementia in Europe: A collaborative study of 1980-1990 findings. International Journal of Epidemiology, 20, 736-748.

Hommel, B., Li, K. Z. H., \& Li, S.-C. (2004). Visual search across the life span. Developmental Psychology, 40, 545-558.

Kaufman, E. L., Lord, M. W., Reese, T. W., \& Volkman, J. (1949). The discrimination of visual number. American Journal of Psychology, 62, 498-525.

Kaufmann, L., Montanes, P., Jacquier, M., Matallana, D., Eibl, G., \& Delazer, M. (2002). About the relationship between basic numerical processing and arithmetics in early Alzheimer's disease - A follow-up study. Brain and Cognition, 48, 398-405. 
Kramer, A. F., \& Madden, D. J. (2008). Attention. In F. I. M. Craik and T. A. Salthouse (Eds.), The handbook of aging and cognition ( $3^{\text {rd }}$ ed., pp. 189-249). New York: Psychology Press.

Laslett, P. (1997). Interpreting the demographic changes. Philosophical Transactions of the Royal Society of London, Series B, 352, 1805-1809.

Lee, A., Boone, K. B., Lesser, I., Wohl, M., Wilkins, S., \& Parks, C. (2000). Performance of older depressed patients on two cognitive malingering tests: False positive rates for the Rey 15-item memorization and dot counting tests. Clinical Neuropsychologist, 14, 303-308.

Levinoff, E. J., Li, K. Z. H., Murtha, S., \& Chertkow, H. (2004). Selective attention impairments in Alzheimer’s disease: Evidence for dissociable components. Neuropsychology, 18, 580-588.

Lezak, M. D., Howieson, D. B., \& Loring, D. W. (2004). Neuropsychological assessment ( $4^{\text {th }}$ ed.). New York: Oxford University Press.

Logan, G. D., \& Zbrodoff, N. J. (2003). Subitzing and similarity: Toward a pattern-matching theory of enumeration. Psychonomic Bulletin \& Review, 10, 676-682.

Madden, D. J., \& Whiting, W. L. (2004). Age-related changes in visual attention. In P. T. Costa \& I. C. Siegler (Eds.), Recent advances in psychology and aging (pp. 41-84). Amsterdam: Elsevier.

Mandler, G., \& Shebo, B. J. (1982). Subitizing: An analysis of its component processes. Journal of Experimental Psychology: General, 111, 1-22.

Maylor, E. A., \& Watson, D. G. (2005). Aging and the ability to ignore irrelevant information in visual search and enumeration tasks. In J. Duncan, L. Phillips \& P. McLeod (Eds.), Measuring the mind: Speed, control, and age (pp. 59-87). Oxford, UK: Oxford University Press. 
Maylor, E. A., Watson, D. G., \& Muller, Z. (2005). Effects of Alzheimer’s disease on visual enumeration. Journal of Gerontology Series B: Psychological Sciences and Social Sciences, 60, P129-P135.

McKhann, G., Drachmann, P., Folstein, M., Katzman, R., Price, P., \& Stadler, E. (1984). Clinical diagnosis of Alzheimer's disease: Report of the NINCDS-ADRDA work group under the auspices of the Department of Health and Human Services task force on Alzheimer’s disease. Neurology, 34, 939-944.

Nebes, R. D. (1992). Cognitive dysfunction in Alzheimer's disease. In F. I. M. Craik and T. A. Salthouse (Eds.), The handbook of aging and cognition ( $1^{\text {st }}$ ed., pp. 373-446). Hillsdale, NJ: Erlbaum.

Nebes, R. D., \& Brady, C. B. (1989). Focused and divided attention in Alzheimer’s disease. Cortex, 25, 305-315.

Nebes, R. D., \& Brady, C. B. (1992). Generalized cognitive slowing and severity of dementia in Alzheimer's disease: Implications for the interpretation of response-time data. Journal of Clinical and Experimental Neuropsychology, 14, 317-326.

Nebes, R. D., Brady, C. B., \& Reynolds, C. F., III. (1992). Cognitive slowing in Alzheimer's disease and geriatric depression. Journal of Gerontology: Psychological Sciences, 47, P331-P336.

Nebes, R. D., Butters, M. A., Mulsant, B. H., Pollack, B. G., Zmuda, M. D., Houck, P. R., \& Reynolds, C. F., III. (2000). Decreased working memory and processing speed mediate cognitive impairment in geriatric depression. Psychological Medicine, 30, 679-691.

Nebes, R. D., Halligan, E. M., Rosen, J., \& Reynolds, C. F., III. (1998). Cognitive and motor slowing in Alzheimer's disease and geriatric depression. Journal of the International Neuropsychological Society, 4, 426-434. 
Nebes, R. D., \& Madden, D. J. (1988). Different patterns of cognitive slowing produced by Alzheimer's disease and normal aging. Psychology and Aging, 3, 102-104.

Nestor, P. G., Parasuraman, R., \& Haxby, J. V. (1991). Speed of information processing and attention in early Alzheimer’s dementia. Developmental Neuropsychology, 7, 243-256.

Ott, A., Breteler, M. M. B., van Harskamp, F., Claus, J. J., van der Cammen, T. J. M., Grobbee, D. E., \& Hofman, A. (1995). Prevalence of Alzheimer's disease and vascular dementia: association with education. The Rotterdam study. British Medical Journal, 310, 970-973.

Parasuraman, R., \& Greenwood, P. M. (1998). Selective attention in aging and dementia. In R. Parasuraman (Ed.), The attentive brain (pp. 461-487). Cambridge, MA: MIT Press.

Parasuraman, R., Greenwood, P. M., Haxby, J. V., \& Grady, C. L. (1992). Visuospatial attention in dementia of the Alzheimer type. Brain, 115, 711-733.

Parasuraman, R., \& Haxby, J. V. (1993). Attention and brain function in Alzheimer’s disease: A review. Neuropsychology, 7, 242-272.

Perry, R. J., \& Hodges, J. R. (1999). Attention and executive deficits in Alzheimer's disease: A critical review. Brain, 122, 383-404.

Piazza, M., Giacomini, E., Le Bihan, D., \& Dehaene, S. (2003). Single-trial classification of parallel pre-attentive and serial attentive processes using functional magnetic resonance imaging. Proceedings of the Royal Society of London, B, 270, 1237-1245.

Piazza, M., Mechelli, A., Butterworth, B., \& Price, C. J. (2002). Are subitizing and counting implemented as separate or functionally overlapping processes? NeuroImage, 15, 435446.

Plude, D. J., \& Doussard-Roosevelt, J. A. (1989). Aging, selective attention, and feature integration. Psychology and Aging, 4, 98-105. 
Rastle, K., \& Davis, M. H. (2002). On the complexities of measuring naming. Journal of Experimental Psychology: Human Perception and Performance, 28, 307-314.

Reitan, R. M. (1958). Validity of the Trail Making test as an indicator of organic brain damage. Perceptual and Motor Skills, 8, 271-276.

Rizzo, M., Anderson, S. W., Dawson, J., Myers, R., \& Ball, K. (2000). Visual attention impairments in Alzheimer's disease. Neurology, 54, 1954-1959.

Rocca, P., Calvarese, P., Faggiano, F., Marchiaro, L., Mathis, F., Rivoira, E., Taricco, B., \& Bogetta, F. (2005). Citalopram versus sertraline in late-life nonmajor clinically significant depression: A 1-year follow-up clinical trial. Journal of Clinical Psychiatry, 66, 360-369.

Rösler, A., Mapstone, M., Hays-Wicklund, A., Gitelman, D. R., \& Weintraub, S. (2005). The “zoom lens” of focal attention in visual search: Changes in aging and Alzheimer’s disease. Cortex, 41, 512-519.

Sagi, D., \& Julesz, B. (1984). Detection versus discrimination of visual orientation. Perception, 13, 619-628.

Salthouse, T. A. (1985). A theory of cognitive aging. Amsterdam: North-Holland.

Sathian, K., Simon, T. J., Peterson, S., Patel, G. A., Hoffman, J. M., \& Grafton, S. T. (1999). Neural evidence linking visual object enumeration and attention. Journal of Cognitive Neuroscience, $11,36-51$.

Schneider, J. (2002). Near vision test card. Retrieved November 16, 2007, from http://www.i-see.org/block_letter_eye_chart.pdf

Sheikh, J. I., \& Yesavage, J. A. (1986). Geriatric Depression Scale (GDS): Recent evidence and development of a shorter version. In T. L. Brink (Ed.), Clinical gerontology: A guide to assessment and intervention (pp. 165-173). New York: The Haworth Press. 
Sheline, Y. I., Barch, D. M., Garcia, K., Gersing, K., Pieper, C., Welsh-Bohmer, K., Steffens, D. C., \& Doraiswamy, P. M. (2006). Cognitive function in late life depression: Relationships to depression severity, cerebrovascular risk factors and processing speed. Biological Psychiatry, 60, 58-65.

Sliwinski, M. (1997). Aging and counting speed: Evidence for process-specific slowing. Psychology and Aging, 12, 38-49.

Sliwinski, M. J., Hofer, S. M., Hall, C., Buschke, H., \& Lipton, R. B. (2003). Modeling memory decline in older adults: The importance of preclinical dementia, attrition, and chronological age. Psychology and Aging, 18, 658-671.

Steffens, D. C., \& Potter, G. G. (2008). Geriatric depression and cognitive impairment. Psychological Medicine, 38, 163-175.

Stevens, T., Livingston, G., Kitchen, G., Manela, M., Walker, Z., \& Katona, C. (2002). Islington study of dementia subtypes in the community. British Journal of Psychiatry, 180, 270-276.

Tales, A., Butler, S. R., Fossey, J., Gilchrist, I. D., Jones, R. W., \& Troscianko, T. (2002). Visual search in Alzheimer's disease: A deficiency in processing conjunctions of features. Neuropsychologia, 40, 1849-1857.

Tales, A., Snowden, R. J., Brown, M., \& Wilcock, G. (2006). Alerting and orienting in Alzheimer's disease. Neuropsychology, 20, 752-756.

Thomas, A. J., \& O’Brien, J. T. (2008). Depression and cognition in older adults. Current Opinion in Psychiatry, 21, 8-13.

Trick, L. M., \& Enns, J. T. (1997). Measuring preattentive processes: When is pop-out not enough? Visual Cognition, 4, 163-198. 
Trick, L. M., \& Pylyshyn, Z. W. (1993). What enumeration studies can show us about spatial attention: Evidence for limited capacity preattentive processing. Journal of Experimental Psychology: Human Perception and Performance, 19, 331-351.

Trick, L. M., \& Pylyshyn, Z. W. (1994). Why are small and large numbers enumerated differently? A limited-capacity preattentive stage in vision. Psychological Review, 101, 80-102.

Tuholski, S. W., Engle, R. W., \& Baylis, G. C. (2001). Individual differences in working memory capacity and enumeration. Memory \& Cognition, 29, 484-492.

Watson, D. G., \& Humphreys, G. W. (1999). The magic number four and temporo-parietal damage: Neurological impairments in counting targets amongst distractors. Cognitive Neuropsychology, 16, 609-629.

Watson, D. G., Maylor, E. A., Allen, G., \& Bruce, L. A. M. (2007). Early visual tagging: Effects of target-distractor similarity and old age on search, subitization, and counting. Journal of Experimental Psychology: Human Perception and Performance, 33, 549569.

Watson, D. G., Maylor, E. A., \& Bruce, L. A. M. (2005a). Effects of age on searching for and enumerating targets that cannot be detected efficiently. Quarterly Journal of Experimental Psychology A, 58(A), 1119-1142.

Watson, D. G., Maylor, E. A., \& Bruce, L. A. M. (2005b). Search, enumeration, and aging: Eye movement requirements cause age-equivalent performance in enumeration but not in search tasks. Psychology and Aging, 20, 226-240.

Watson, D. G., Maylor, E. A., \& Bruce, L. A. M. (2007). The role of eye movements in subitizing and counting. Journal of Experimental Psychology: Human Perception and Performance, 33, 1389-1399. 
Watson, D. G., Maylor, E. A., \& Manson, N. J. (2002). Aging and enumeration: A selective deficit for the subitization of targets among distractors. Psychology and Aging, 17, 496504.

Woods, R. T. (1999). Mental health problems in late life. In R. T. Woods (Ed.), Psychological problems of ageing: Assessment, treatment and care (pp. 73-110). Chichester: Wiley. 


\section{Footnotes}

${ }^{1}$ Testing on Part B of the TMT had to be abandoned before completion for five of the AD patients for whom the task proved too difficult. Their data are therefore not included in the means for either TMT B or TMT B-A in Table 1. Not surprisingly, these patients were significantly slower on Part A than the 14 AD patients who completed both Parts A and B $(M=169.4$ and 95.6 s, respectively; $p<.05)$, but the pattern of significant differences for TMT A shown in Table 1 was the same whether or not the five AD patients were included. However, it should be recognized that the means for the AD group for TMT B and TMT BA probably underestimate the group's actual deficits.

${ }^{2} \mathrm{~A}$ similar technique has been used successfully in the past with young adults (e.g., Watson, Maylor, \& Bruce, 2007), older adults (e.g., Watson et al., 2002), and AD patients (Maylor et al., 2005). It is preferable to other methodologies used in enumeration studies for a number of reasons. For example, some require participants to press a number key themselves corresponding to numerosity (e.g., Sliwinski, 1997), which contaminates enumeration times with times to locate and select the appropriate key, and increases task demands. Others employ voice keys (e.g., Nebes et al., 1992) but these do not reliably detect acoustic onsets (see Rastle \& Davis, 2002) and also occasionally trigger in response to other noises or fail to trigger in response to the participant's voice onset.

${ }^{3}$ These participants tended to be those who performed poorly on Part B of the TMT (indicative of impaired executive functioning).

${ }^{4}$ Subitizing span was determined by fitting a bilinear function to the mean correct RTs for numerosities 1 to 8 . The best fit was achieved by using an optimization procedure (for additional details, see Watson, Maylor, \& Bruce, 2005a; Watson, Maylor, \& Manson, 2002) that minimized the mean square error between the model prediction and observed data by modifying the model's 4 free parameters (2 slopes and 2 intercepts). Following 
optimization, the subitizing span was taken to be the $\mathrm{x}$-axis value corresponding to the bilinear flex point (where the two linear functions meet), which represents the point at which the subitization process was replaced by the slower serial counting process.

${ }^{5} \mathrm{By}$ far the slowest counting rate was produced by a control participant whose rate was 2.6 standard deviations slower than the overall mean for the entire sample. Without this participant, the mean counting rate for the control group was 345 ms/item.

${ }^{6}$ Data from the three AD patients who completed only two blocks of enumeration trials are not included in Figure 5.

${ }^{7}$ Erroneous responses tended to be smaller rather than larger than the correct numerosity, particularly with distractors present. Thus the overall difference between correct and erroneous responses for numerosities 2-8 was -0.28 without distractors (cf. -0.26 in Experiment 1) and -0.51 with distractors.

${ }^{8}$ One AD patient was exceptionally slow at enumerating dots on a die, with a mean RT 2.8 standard deviations longer than the mean for the AD group and 4.5 standard deviations longer than the mean for the whole sample. Without this participant, the mean RT for the AD group was reduced from 766 to $652 \mathrm{~ms}$ but the ANOVA results were unaffected. 
Table 1

Numbers of Participants Whose Enumeration Data were Included in Experiment 1, Demographic Information, and Mean Scores and Significance of Group Effects in One-Way Analyses of Variance on Background Measures

\begin{tabular}{|c|c|c|c|c|c|}
\hline Measure & $\mathrm{AD}$ & VAD & DEP & $\mathrm{CON}$ & Group effect \\
\hline $\mathrm{N}$ (females/males) & $19(9 / 10)$ & $6(3 / 3)$ & $15(7 / 8)$ & $21(15 / 6)$ & $\begin{array}{l}-- \\
\end{array}$ \\
\hline Age (years) & 79.1 & 77.8 & 76.3 & 79.1 & ns \\
\hline Education (years) & 9.8 & 10.2 & 10.3 & 11.1 & ns \\
\hline Health $^{\mathrm{a}}$ & 4.0 & 3.7 & 3.3 & 4.0 & ns \\
\hline Near Vision ${ }^{\mathrm{b}}$ & $16 / 32$ & $16 / 32$ & $16 / 32$ & $16 / 32$ & ns \\
\hline GDS- $15^{\mathrm{c}}$ & 4.0 & 4.2 & $5.7^{\mathrm{a}}$ & $2.1^{\mathrm{a}}$ & $*$ \\
\hline $\mathrm{MMSE}^{\mathrm{d}}$ & $22.8^{\mathrm{ab}}$ & $23.7^{c}$ & $26.9^{\mathrm{a}}$ & $28.5^{\mathrm{bc}}$ & $* *$ \\
\hline LCT $_{\text {correct }}{ }^{\mathrm{e}}$ & $39.2^{\mathrm{a}}$ & $37.0^{\mathrm{abc}}$ & $39.3^{\mathrm{b}}$ & $39.1^{\mathrm{c}}$ & $* *$ \\
\hline LCT time $(\mathrm{s})^{\mathrm{f}}$ & $86.5^{\mathrm{a}}$ & 65.8 & 63.4 & $51.4^{\mathrm{a}}$ & $* *$ \\
\hline TMT A (s) & $115.0^{\mathrm{ab}}$ & 85.7 & $56.2^{\mathrm{b}}$ & $49.7^{\mathrm{a}}$ & $* *$ \\
\hline TMT B (s) ${ }^{\mathrm{h}}$ & $305.4^{\mathrm{ab}}$ & $314.3^{\mathrm{cd}}$ & $162.6^{\mathrm{ac}}$ & $107.6^{\text {bd }}$ & $* *$ \\
\hline TMT B-A (s) & $209.8^{\mathrm{ab}}$ & $228.7^{\mathrm{cd}}$ & $106.4^{\mathrm{ac}}$ & $57.9^{\text {bd }}$ & $* *$ \\
\hline Counting 1-10 (s) & 3.1 & 2.6 & 2.6 & 3.2 & ns \\
\hline Counting 1-20 (s) & 6.7 & 5.8 & 6.4 & 7.3 & ns \\
\hline
\end{tabular}

Note. Within each row, scores with the same superscript letter differ significantly at $p<.05$ on Tukey HSD post hoc tests. AD = Alzheimer's Disease; VAD = Vascular Dementia; DEP $=$ Depressed; $\mathrm{CON}=$ Controls .

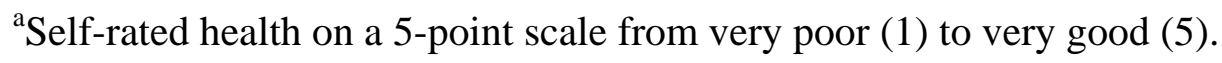


${ }^{b}$ Visual acuity as measured by the Near Vision Test Card (Schneider, 2002) viewed at a distance of 16 inches $(40 \mathrm{~cm})$ whilst wearing corrective glasses and expressed as scores ranging from 16/160 (low acuity) to 16/16 (high acuity); median performance.

${ }^{\mathrm{c}}$ The 15-item short form of the Geriatric Depression Scale (Sheikh \& Yesavage, 1986); maximum $=15$.

${ }^{\mathrm{d}}$ Mini-Mental State Examination (Folstein, Folstein, \& McHugh, 1975); maximum = 30. ${ }^{\mathrm{e}}$ Correct responses (hits) on a Letter Cancellation Task based on visual search tests described by Lezak, Howieson, and Loring (2004), with 40 targets (the letter “A”) and 40 distractors (other random letters).

${ }^{\mathrm{f}}$ Time taken to complete Letter Cancellation Task.

${ }^{\text {g}}$ Trail Making Test Part A (Reitan, 1958).

${ }^{\mathrm{h}}$ Trail Making Test Part B (Rietan, 1958), not including 5 AD patients who could not perform the test.

${ }^{\mathrm{i} D i f f e r e n c e ~ b e t w e e n ~ T r a i l ~ M a k i n g ~ T e s t ~ P a r t s ~ A ~ a n d ~ B ~(s e e ~ C o r r i g a n ~ \& ~ H i n k e l d e y, ~ 1987), ~ a n ~}$ estimate of executive functioning; data missing for $5 \mathrm{AD}$ patients.

${ }^{\mathrm{j}}$ Time taken to count aloud from 1-10 (average of two trials).

${ }^{\mathrm{k}}$ Time taken to count aloud from 1-20 (average of two trials).

ns $=$ not significant $(p>.05) .{ }^{*} p<.05 .{ }^{* *} p<.01$. 
Table 2

Numbers of Participants Whose Enumeration Data were Included in Experiment 2, Demographic Information, and Mean Scores and Significance of Group Effects in One-Way Analyses of Variance on Background Measures Collected in Experiment 1

\begin{tabular}{|c|c|c|c|}
\hline Measure & $\mathrm{AD}$ & $\mathrm{CON}$ & Group effect \\
\hline $\mathrm{N}$ (females/males) & $11(4 / 7)$ & $18(13 / 5)$ & $\begin{array}{l}-- \\
\end{array}$ \\
\hline Age (years) & 81.4 & 78.7 & ns \\
\hline Education (years) & 9.8 & 11.2 & $*$ \\
\hline Health $^{\mathrm{a}}$ & 4.4 & 3.9 & ns \\
\hline Near Vision ${ }^{\mathrm{b}}$ & $16 / 40$ & $16 / 32$ & ns \\
\hline GDS- $15^{\mathrm{c}}$ & $2.9(3.0)$ & $2.1(2.1)$ & ns \\
\hline MMSE $^{\mathrm{d}}$ & $23.7(23.2)$ & $28.6(28.6)$ & $* *$ \\
\hline LCT correct $^{\mathrm{e}}$ & 39.2 & 39.2 & ns \\
\hline LCT time $(\mathrm{s})^{\mathrm{f}}$ & 89.3 & 49.3 & $* *$ \\
\hline TMT A $(s)^{g}$ & 103.5 & 48.2 & $* *$ \\
\hline TMT B (s) ${ }^{\mathrm{h}}$ & 297.6 & 103.5 & $* *$ \\
\hline TMT B-A (s) ${ }^{\mathrm{i}}$ & 215.2 & 55.3 & $* *$ \\
\hline Counting 1-10 (s) ${ }^{\mathrm{j}}$ & 3.3 & 3.3 & ns \\
\hline Counting 1-20 (s) ${ }^{\mathrm{k}}$ & 7.1 & 7.4 & ns \\
\hline
\end{tabular}

Note. $\mathrm{AD}=$ Alzheimer's Disease; $\mathrm{CON}=$ Controls.

${ }^{\mathrm{a}-\mathrm{k}}$ See Table 1 for details. GDS-15 and MMSE tests were administered again in Experiment 2 (new scores in parentheses). TMT B and TMT B-A do not include 2 AD patients who could not perform TMT B.

ns $=$ not significant $(p>.05) .{ }^{*} p<.05 .{ }^{* *} p<.01$. 
Figure Captions

Figure 1. Examples of stimulus displays in the enumeration tasks. Top panel: Standard enumeration of 1-9 randomly positioned filled circles (Experiments 1 and 2). Middle panel: Enumeration of 1-9 unfilled circles among 19-11 (respectively) Xs (Experiment 2). [The visual search displays of Experiment 2 were the same except for the numbers of Os (0/1) and Xs (20/19).] Bottom panel: Enumeration of 1-6 dots on a die (Experiment 2).

Figure 2. Mean percentage error rates for patients with Alzheimer's disease (AD), patients with vascular dementia (VAD), depressed patients (DEP), and age-matched controls (CON) as a function of numerosity for the visual enumeration task in Experiment 1.

Figure 3. Mean correct response times (RTs) in ms for patients with Alzheimer's disease (AD), patients with vascular dementia (VAD), depressed patients (DEP), and age-matched controls (CON) as a function of numerosity for the visual enumeration task in Experiment 1.

Figure 4. Mean differences (with standard error bars) between mean correct response times (RTs) for numerosities 1 and 2 (RT2 minus RT1 in ms) in Experiment 1 for patients with Alzheimer's disease (AD), patients with vascular dementia (VAD), depressed patients (DEP), age-matched controls (CON), and young adults (see text for details) for comparison.

Figure 5. Mean correct response times (RTs) in ms for patients with Alzheimer's disease (AD) and age-matched controls (CON) as a function of numerosity for each of the three blocks of enumeration trials in Experiment 1. 
Figure 6. Mean percentage error rates for patients with Alzheimer's disease (AD) and agematched controls (CON) as a function of numerosity for enumerating Os (solid lines) and enumerating Os among Xs (dashed lines) in Experiment 2.

Figure 7. Mean correct response times (RTs) in ms for patients with Alzheimer's disease (AD) and age-matched controls (CON) as a function of numerosity for enumerating Os (solid lines) and enumerating Os among Xs (dashed lines) in Experiment 2.

Figure 8. Mean differences (with standard error bars) between mean correct response times (RTs) for numerosities 1 and 2 (RT2 minus RT1 in ms) for enumerating Os alone, Os among Xs, and dots on a die, for patients with Alzheimer's disease (AD) and age-matched controls (CON) in Experiment 2.

Figure 9. Mean correct response times (RTs) in ms for patients with Alzheimer's disease (AD) and age-matched controls (CON) as a function of numerosity for enumerating 1-6 dots on a die in Experiment 2.

Figure 10. Mean correct response times (RTs) in ms for patients with Alzheimer's disease (AD) and age-matched controls (CON) as a function of display size and absence/presence of a target $\mathrm{O}$ among Xs for the visual search task in Experiment 2. 
Figure 1.
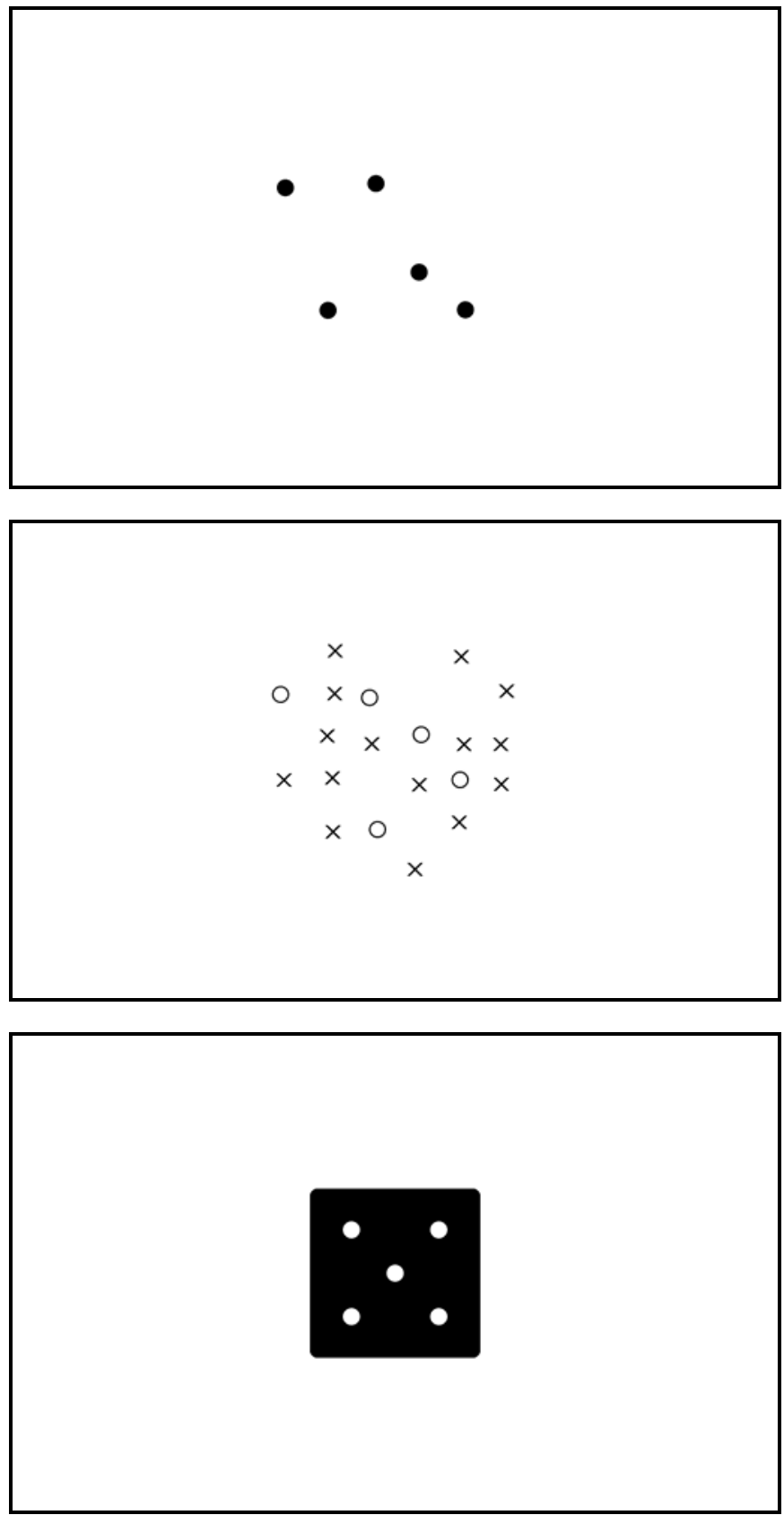
Figure 2.

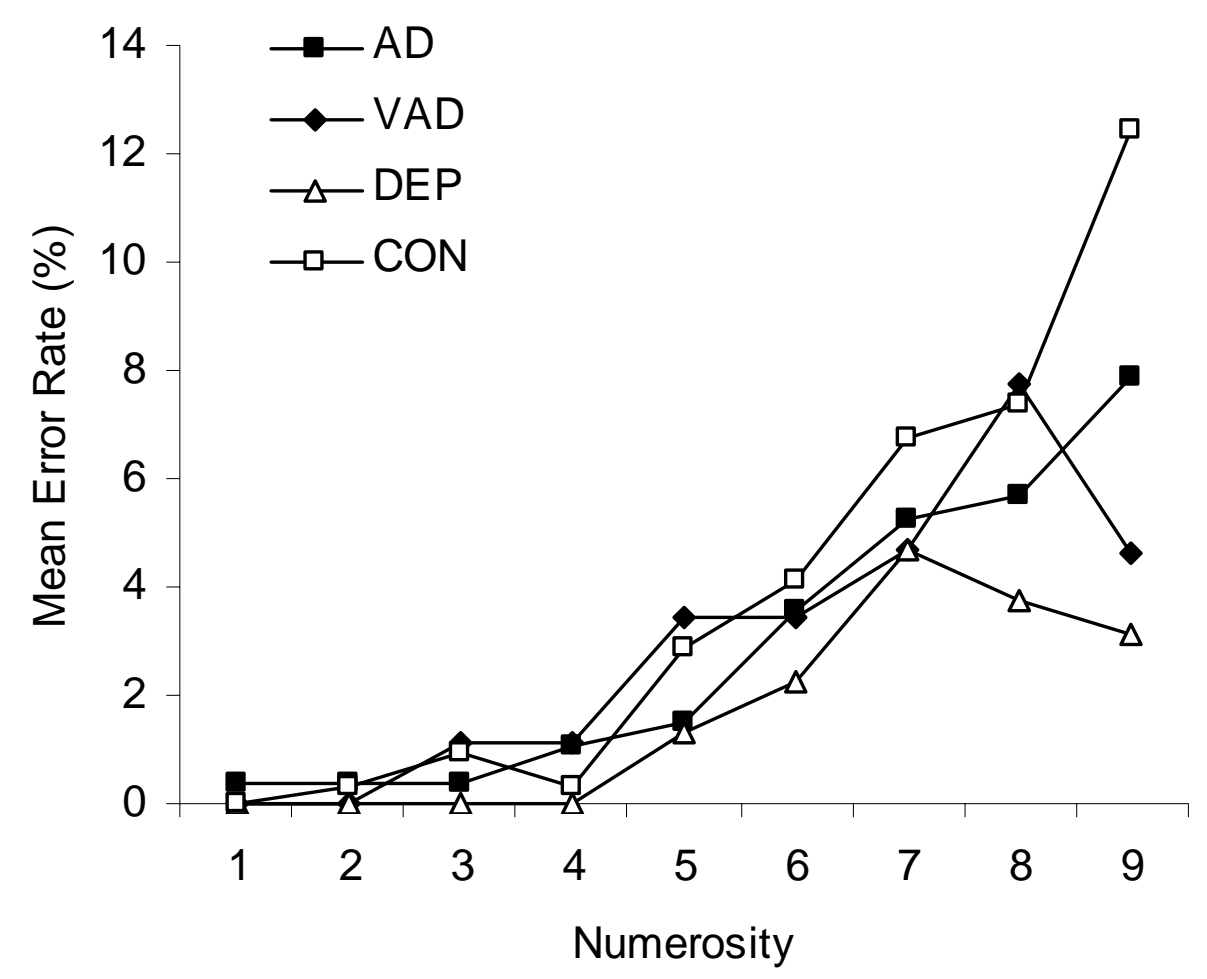


Figure 3.

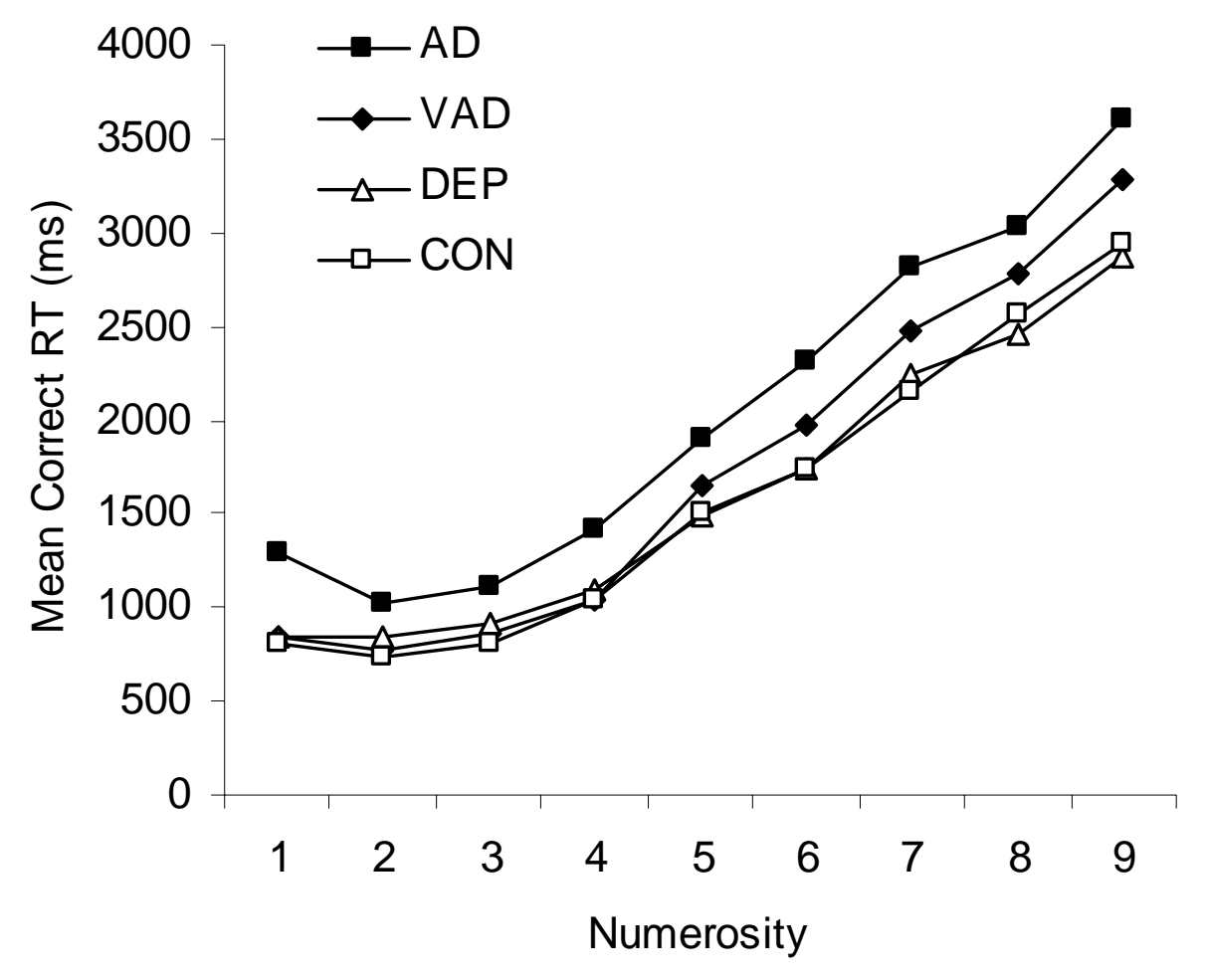


Figure 4.

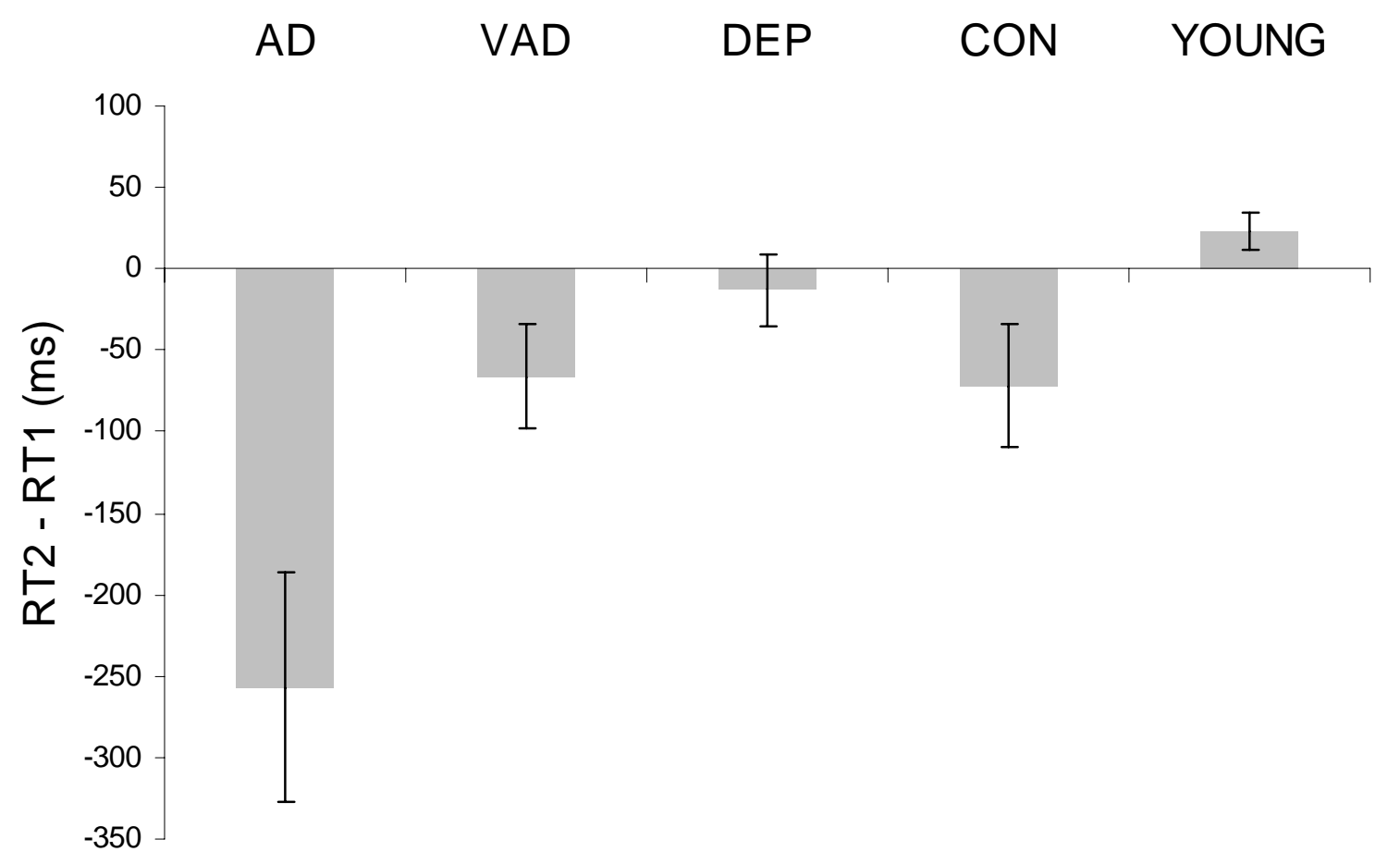


Figure 5.

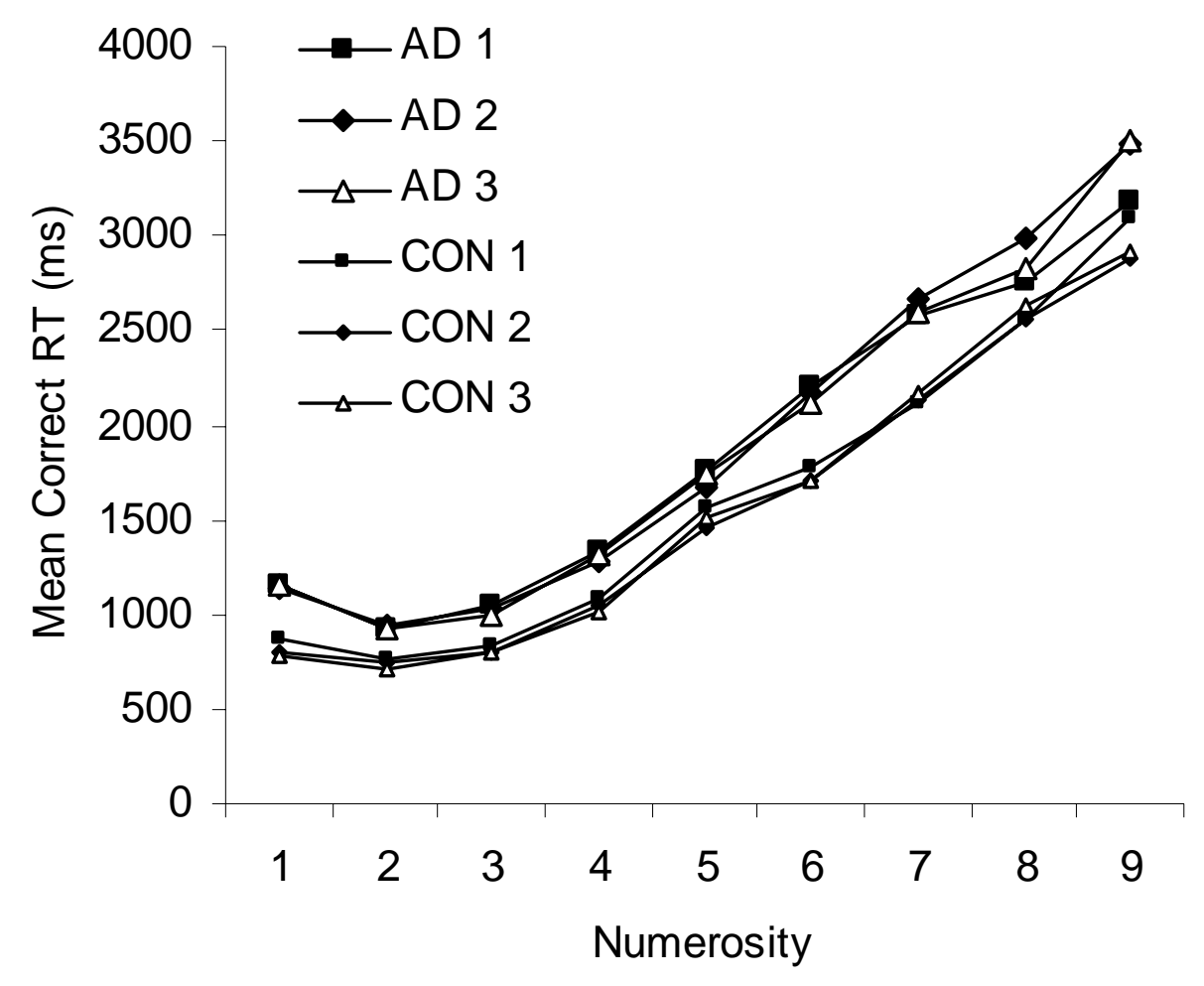


Figure 6.

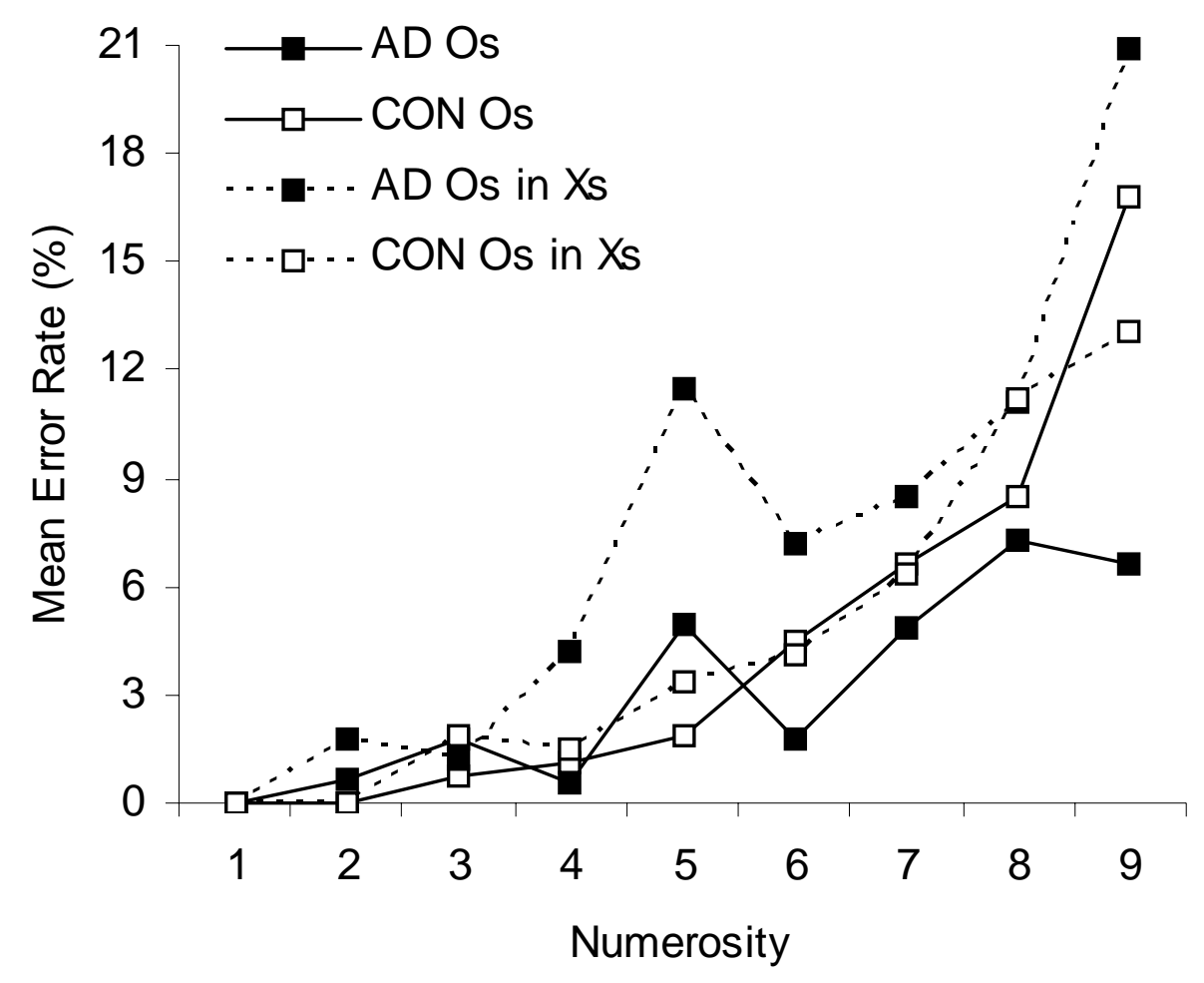


Figure 7.

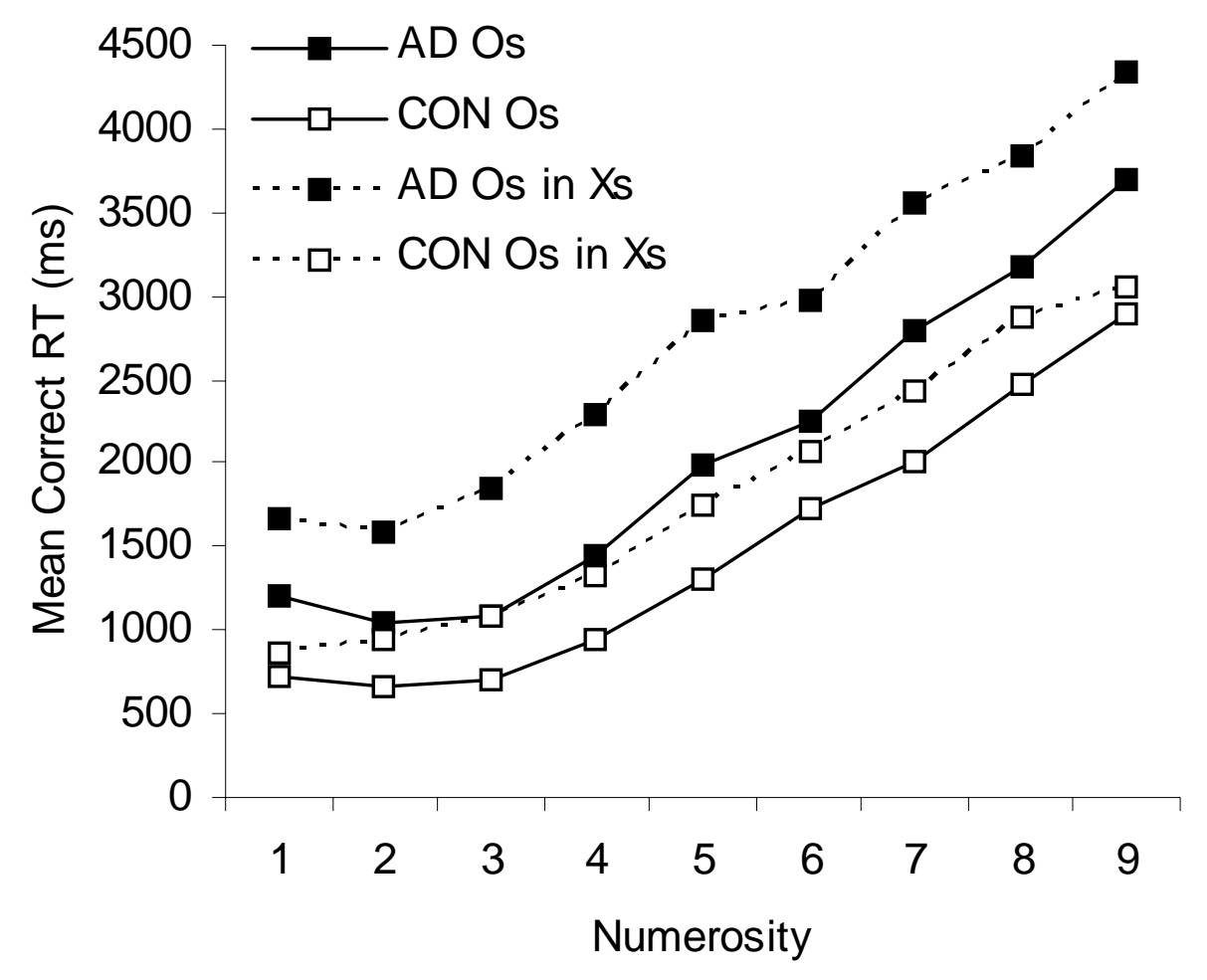


Figure 8.

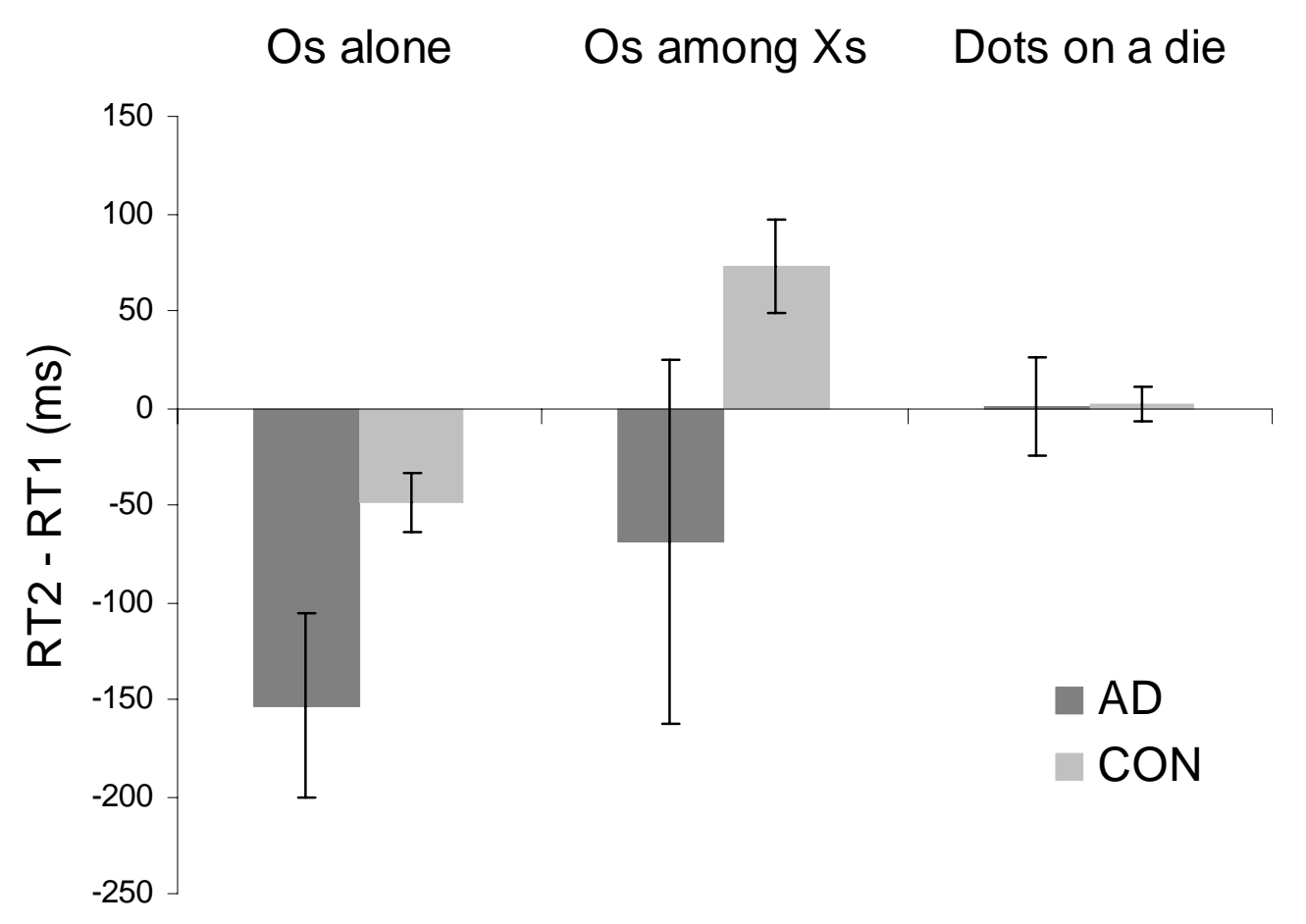


Figure 9.

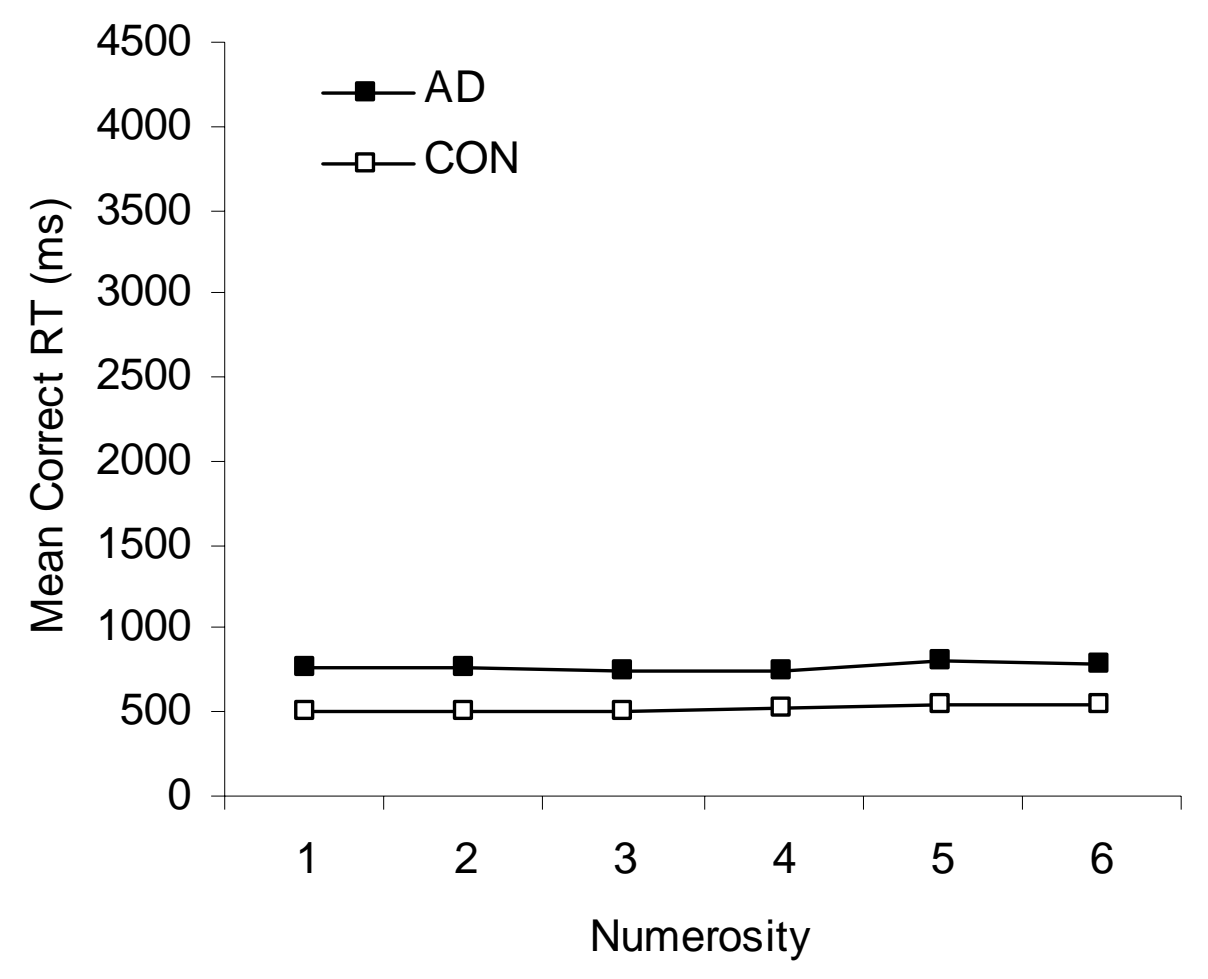


Figure 10.

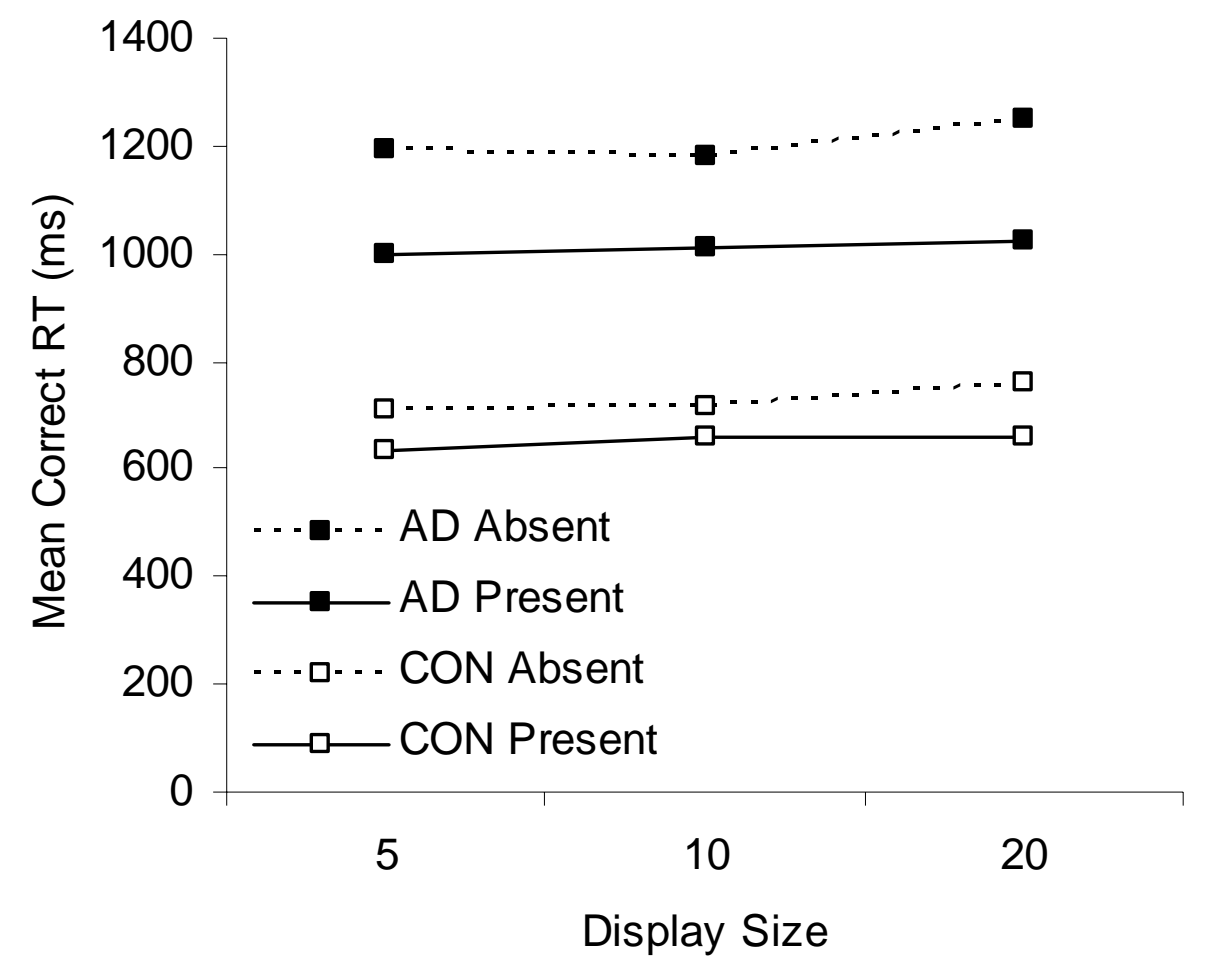

